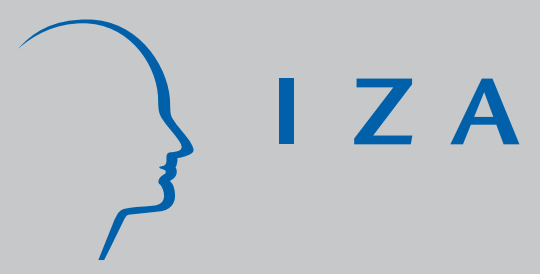

IZADP No. 4039

\title{
Coordination under the Shadow of Career Concerns
}

Alexander K. Koch

Albrecht Morgenstern

February 2009 


\title{
Coordination under the Shadow of Career Concerns
}

\author{
Alexander K. Koch \\ University of Aarhus \\ and IZA
Albrecht Morgenstern
German Federal Chancellery
and IZA

Discussion Paper No. 4039

February 2009

\author{
IZA \\ P.O. Box 7240 \\ 53072 Bonn \\ Germany \\ Phone: +49-228-3894-0 \\ Fax: +49-228-3894-180 \\ E-mail: iza@iza.org
}

\begin{abstract}
Any opinions expressed here are those of the author(s) and not those of IZA. Research published in this series may include views on policy, but the institute itself takes no institutional policy positions.

The Institute for the Study of Labor (IZA) in Bonn is a local and virtual international research center and a place of communication between science, politics and business. IZA is an independent nonprofit organization supported by Deutsche Post Foundation. The center is associated with the University of Bonn and offers a stimulating research environment through its international network, workshops and conferences, data service, project support, research visits and doctoral program. IZA engages in (i) original and internationally competitive research in all fields of labor economics, (ii) development of policy concepts, and (iii) dissemination of research results and concepts to the interested public.
\end{abstract}

IZA Discussion Papers often represent preliminary work and are circulated to encourage discussion. Citation of such a paper should account for its provisional character. A revised version may be available directly from the author. 
IZA Discussion Paper No. 4039

February 2009

\section{ABSTRACT}

\section{Coordination under the Shadow of Career Concerns ${ }^{*}$}

To innovate, employees need to develop novel ideas and coordinate with each other to turn these ideas into better products and services. Work outcomes provide signals about employees' abilities to the labor market, and therefore career concerns arise. These can both be 'good' (enhancing incentives for effort in developing ideas) and 'bad' (preventing voluntary coordination). Our model shows how the firm designs its explicit incentive system and organizes work processes to take these conflicting forces into account. The comparative statics results suggest a link between the increased use of teams and recent changes in labor market returns to skills.

JEL Classification: D86, J30, L14, L20, M12, O30

Keywords: career concerns, group incentives, knowledge work, reputation, teams

Corresponding author:

Alexander K. Koch

School of Economics and Management

University of Aarhus

Building 1322

8000 Aarhus C

Denmark

E-mail: akoch@econ.au.dk

\footnotetext{
${ }^{*}$ We received helpful comments on this project from Peter Ove Christensen, Guido Friebel, Robert Gibbons, Francine Lafontaine, Julia Nafziger, Paul Oyer, and Leonidas Enrique de la Rosa. The opinions expressed in this paper are those of the authors and do not necessarily reflect the views of the Federal Chancellery.
} 


\section{Introduction}

A firm thrives if it fosters innovation that leads to improved products and services, streamlined production processes or enhanced business strategies. To achieve these goals, members of the organization have to i) expend effort in developing novel ideas and designs; ii) agree to coordinate with each other to implement these ideas and designs. Because the quality of implemented designs and products that employees are associated with influences their labor market opportunities, career concerns (Fama 1980, Holmström 1982/99) arise. Employees thus have a stake in their work projects that goes beyond the short-run rewards offered through the compensation scheme of the firm.

These career concerns are a mixed blessing for firms dealing with knowledge workers, as our model shows. On the one hand, they help motivate employees to exert effort in developing novel ideas and designs (knowledge inputs). On the other hand, career concerns can stifle voluntary coordination among employees, and thereby prevent high-quality knowledge inputs from being turned into product or process improvements. Remarkably, such situations where employees fail to coordinate arise even if there is no form of competition between agents and an agent experiences no utility cost when coordinating with a colleague.

So how does a firm design its explicit compensation scheme to take these conflicting forces into account? The key result in the paper is that either group-based incentives or team production are optimal - even though they offer opportunities for employees to free-ride on the effort of a colleague. The advantage of these schemes relative to compensation based on only an individual's own performance is that they prevent situations where voluntary coordination among employees breaks down. Specifically, group-based incentives are optimal with relatively weak career concerns, whereas relatively strong career concerns lead to the adoption of team production. As we argue, this comparative statics result suggests a link between the increased use of teams and recent changes in labor market returns to skills.

Communication among employees and coordination of their inputs to the production process are essential for transforming innovative ideas into new or enhanced products or processes (e.g. West 2002, West and Tjosvold 2003, Janssen, van de Vliert, and West 2004). This is particularly relevant for knowledge-intensive firms (e.g. Despres and Hiltrop 1995, Mohrman, Cohen, and Mohrman 1995, Faraj and Sproull 2000, Paulus and Yang 2000, Lawler 2003, Foray 2004). To create or improve the complex products and systems that these firms rely on, employees need to incorporate ideas and designs that are to a large extent tacit knowledge bound to 
the person who developed them $L^{1}$ Implementing these ideas and designs (knowledge inputs) requires project members to communicate closely with each other and that they adapt their respective inputs to the production process so that they are mutually compatible. Thompson (1967) describes this as "reciprocal interdependence" that calls for coordination by "mutual adjustment". Because parties rely on each other to implement their knowledge inputs, it is crucial for the organization that employees are willing to coordinate: the tacit nature of knowledge inputs "creates strict dependence between the potential value of the intellectual asset (e.g., for a firm or other organization) and the good will of individuals to take deliberate or voluntary action to share it" (Foray 2004, p.73).

Our model captures these elements in a two-period principal-agent setting. In the first period, a firm (the principal) employs two risk neutral individuals protected by limited liability (the agents) to work on a joint project. In the second period, agents receive outside employment offers from the labor market.

Each agent develops a knowledge input for the first-period project that can be of high or low quality - depending on the (unknown) ability of the agent and the (unobservable) effort he puts in. A high-quality knowledge input offers the opportunity to enhance the value of the project along the dimension for which the agent is responsible. Turning it into a better quality of the actual project outcome however requires coordination in the form of "mutual adjustment" of both agents' inputs to the production process. If project members do not agree to coordinate in this way, high-quality knowledge inputs cannot be implemented and there is no quality improvement in the project outcome.

Agents have career concerns because the outcome of their first-period project provides information about their abilities to the labor market in the second period. It is 'good' news about the ability of an agent if his implemented input is of high quality, i.e. he is associated with a creative idea embodied in a product or process. In contrast, it is 'bad' news about the ability of an agent if the project outcome lacks novelty along the dimension for which he is responsible. The better the news about an agent, the more the labor market values his skills.

What each agent earns thus depends on the project outcome in the first period both directly - it supplies the performance measures for the principal's explicit incentive contract - and indirectly, because the labor market uses this information to make wage offers in the second period. The more able an agent is thought to be, the higher the second-period wage. The

\footnotetext{
${ }^{1}$ The concept of tacit knowledge (e.g. Nonaka 1991, Nonaka and Takeuchi 1995) encompasses information that is hard to codify and requires face-to-face communication. It is related to Polanyi's (1966) notion of tacit knowing.
} 
firm and the market cannot directly observe knowledge inputs because they are tacit knowledge that requires close interaction and the specialized expertise of the project members to communicate 2

What our first set of results show is that career concerns have a detrimental effect on the willingness of agents to coordinate in the case where only the own achievement of an individual is rewarded. By not coordinating with a more able colleague, an agent can impose an informational externality - create a 'smoke screen' - behind which he can hide the lacking quality of his own project input. The intuition for the somewhat subtle effect developed in the paper is the following. Faced with a project outcome that lacks novelty along any dimension for which the two agents are responsible, the market is unsure about the underlying cause. Did the outcome arise because both agents truly were not able to generate good ideas? Or was it because they could not agree to coordinate and implement a high-quality knowledge input available to one of the agents? This uncertainty works in favor of an agent who could not develop a high-quality knowledge input: the market is more optimistic about his ability than if coordination occurred and it was revealed that he actually had no good ideas.

As a result, "being in the same boat with the colleague" generates less bad news about an agent than "standing in the shadow of a more successful colleague." This finding is remarkable because it shows that even if agents do not compete with each other and are otherwise disinterested in each others' payoffs, they may impose an informational externality on the joint project outcome to hide bad news about themselves.

We then show that the principal can avoid coordination failure by moving away from rewarding individual achievement only. But such a move introduces the opportunity for agents to free-ride on the effort of the project partner at the stage where knowledge inputs are developed. As this weakens incentives, it becomes more costly to get the agents to exert effort. When designing her explicit compensation scheme the principal therefore needs to take these conflicting forces into account.

This leads to our main results. The optimal contract rewards an agent not only for his own contribution to a project but also for a successfully implemented knowledge input of his colleague. This either occurs explicitly - through group-performance rewards in addition to pay based on individual performance; or implicitly - by organizing production around teams. In the latter case, work processes are organized so that individual performance measures are not available to the principal and compensation, by necessity, is based on the team outcome.

\footnotetext{
${ }^{2}$ As Foray (2004, p.9) puts it, "knowledge is largely unobservable ... tacit knowledge is constantly being reconstituted, so that a vast world remains perpetually invisible."
} 
While both policies avoid the breakdown of voluntary coordination among employees, their wage costs are different. Group-based incentives are optimal when employees' career concerns are relatively weak, and team production is the optimal human-resource policy when career concerns are relatively strong.

This comparative statics result suggests a link between the introduction of innovative humanresource practices and labor market developments that have affected the strength of career concerns. With the rapid technological progress over the last three decades, the importance of "knowledge work" has grown significantly in the advanced economies (e.g. Despres and Hiltrop 1995, OECD 1996, 2001, Foray 2004).

In a parallel development, demand for skilled labor has shifted and made career concerns more prominent: returns to skill have increased, both linked to easily observed components (such as education and experience) as well as linked to measures of unobserved ability (e.g. Juhn, Murphy, and Pierce 1993, Murnane, Willett, and Levy 1995, Bartel and Sicherman 1999, Galor and Moav 2000, Bresnahan, Brynjolfsson, and Hitt 2002).

According to the comparative statics of our model, firms should switch to team production when employees' work outcomes have a strong effect on their labor market opportunities. Indeed, the above changes in labor markets - while complex and in some details controversial (e.g. Card and DiNardo 2002, Autor, Katz, and Kearney 2008) - coincided with the introduction of innovative organizational practices that restructure production processes to rely more on "empowered" teams. For example, in two influential studies Osterman (1994, 2000) estimates that by the mid-1990's more than $60 \%$ of U.S. establishments with over 50 employees adopted teams and other "innovative workplace practices" 3

The outline of the paper is as follows. Section 2 discusses the related literature. In Section 3 we explain in a simplified setting how coordination failure may arise because of agents' career concerns. Section 4 contains the main analysis and characterizes optimal human-resource policies. A discussion of our findings follows in Section 5. All proofs are in Appendix A.

\section{Related literature}

We discuss in turn the contribution of our paper to the literature on career concerns and on multi-agent moral hazard problems.

The career concerns literature originated with the seminal work of Fama (1980) and Holm-

\footnotetext{
${ }^{3}$ For evidence on complementarities between organizational change and demand for skilled labor see e.g. Caroli and Reenen (2001).
} 
ström (1982/99). One strand considers, in a world without explicit contracts, the implications of career concerns for organizational decisions such as task design (e.g. Dewatripont et al. 1999b, Ortega 2003), individual vs. team production (e.g. Jeon 1996, Bar-Isaac 2007), and organizational transparency (e.g. Mukherjee 2008). We connect to this strand with our result that organizing production in teams can be beneficial because it gives less precise signals about agents' inputs to the labor market, and thereby removes reputational conflicts of interest between project members. The implications that we derive for the design of explicit compensation policies contribute to the second strand of the literature, that looks at the interplay of career concerns and explicit incentives (e.g. Gibbons and Murphy 1992, Meyer and Vickers 1997, Auriol, Friebel, and Pechlivanos 2002, Koch and Peyrache 2008a, 2008b). Our findings relate in particular to previous results where "more information" can hurt the principal, e.g. because this weakens career concerns incentives (Dewatripont et al. 1999a, Koch and Peyrache 2008a), undermines the credibility of disciplining actions (Cremer 1995), induces conformist behavior (Prat 2005), or strengthens the ratchet effect in contracting (Meyer, Olsen, and Torsvik 1996).

The classic treatments of multi-agent moral hazard problems (Alchian and Demsetz 1972, Holmström 1982) emphasize the aspect of free-riding in teams.4 But as Hamilton, Nickerson, and Owan (2003, p.466) point out: "Despite obvious concerns about moral hazard, many firms do in fact introduce teams even when individual task assignment is feasible and provide team-based incentives in the hope of improving productivity."

More generally, the literature shows conditions when it can be optimal to reward not only individual performance but rather make compensation contingent on the outcome of other agents' tasks as well: to insure risk-averse agents against common performance shocks (e.g. Holmström 1979, Lazear and Rosen 1981, Green and Stokey 1983, Nalebuff and Stiglitz 1983, Mookherjee 1984, Corts 2008), induce "helping", or internalize production externalities (Itoh 1991, Hemmer 1995). In all these models interdependent incentives are optimal only when there are significant production externalities or costs for each of the multiple activities that an agent engages in.

Repeated interaction between agents may make interdependent incentives optimal as well. In a multi-agent model with costly helping, Auriol, Friebel, and Pechlivanos (2002) show that agents repeatedly interacting with the same principal have an incentive to sabotage co-workers

\footnotetext{
${ }^{4}$ We focus here on incentive theory. See Gibbons (2003) for a recent discussion of the statistical decision perspective of Marschak and Radner's (1972) team theory.
} 
because higher output leads to a ratchet effect that makes the future compensation contract for an individual more demanding. To counteract this, the principal needs to offer group-based incentives. Che and Yoo (2001) show that interdependent incentive schemes or teams may be optimal if individuals interact over a longer period and can impose negative payoff externalities on each other (peer sanctions).

Our model complements these existing rationales for group-based incentives and teams: for these policies to be optimal our setting requires neither repeated interaction between individuals, nor that helping is costly, nor other production externalities.

\section{Career concerns and coordination: A simplified setting}

At the heart of our paper is the insight that career concerns can have a detrimental effect on the coordination process between project members. This section develops the intuition in a simplified setting where agents only face a coordination decision to implement ideas and designs (knowledge inputs) and are motivated only by concerns for their labor-market reputation. We abstract from effort and from contracts that offer explicit incentives. These elements will be introduced when we analyze the fully fledged model in Section 4.

Consider two agents $i=1,2$ who are involved at date 1 in a joint project to improve a product or process. An agent can have either high ability $\left(\theta_{i}=\theta^{H}\right)$ or low ability $\left(\theta_{i}=\theta^{L}<\theta^{H}\right)$, with a common prior of $\operatorname{Prob}\left(\theta_{i}=\theta^{H}\right)=\alpha \in(0,1)$. Hence, the ex ante expected ability of an agent is $E\left[\theta_{i}\right]=\alpha \theta^{H}+(1-\alpha) \theta^{L}$. A high-quality knowledge input offers the opportunity to enhance the quality of the project along the dimension for which the individual who developed this input is responsible. The quality of the knowledge input $k_{i}$ is entirely determined by the ability of an agent: $k_{i}=k\left(\theta_{i}\right)$ with $k\left(\theta_{i}=\theta^{L}\right)=L_{i}$ and $k\left(\theta_{i}=\theta^{H}\right)=H_{i}$.

To turn a a high-quality knowledge input $k_{i}=H_{i}$ into a quality improvement in the project outcome - i.e. realize the potential input quality - requires coordination in the form of "mutual adjustment" of both project members' inputs to the production process. Without such coordination, no quality improvement can be realized and the implemented input of an agent, $x_{i}$, is of low quality. When agents agree to coordinate, the implemented inputs achieve their full potential. That is,

if coordination occurs: implemented input qualities $\left(x_{1}, x_{2}\right)=$ potential input qualities $\left(k_{1}, k_{2}\right)$; if no coordination occurs: implemented input qualities $\left(x_{1}, x_{2}\right)=$ both of low quality $\left(L_{1}, L_{2}\right)$.

Each agent has career concerns because his future earnings depend on the value that the labor market places on his skills. The labor market assesses the ability of an agent based on the 
implemented project outcome. It does not directly observe what potential the knowledge inputs offered because their tacit nature makes this prohibitively costly to verify. For simplicity, we assume that the date-2 continuation utility of an agent equals the expectation that the labor market forms about his ability: $E\left[\theta_{i} \mid\right.$ project outcome].

We abstract in this section from any contracting and compensation issues by assuming that the project is important to agents only because of its impact on the second-period earnings, and that it has no other direct monetary costs or benefits for the agents. In particular, we assume that coordination is without cost to the agents - this makes it clear that our results are not driven by a need to internalize direct helping costs.

To summarize the simple 'bare-bones' career concerns setting of this section: At date 1, the two project members observe the quality of their knowledge inputs, and decide whether or not to coordinate. On his own, an agent can only implement a low-quality input. If the agent turns out to be of high ability, he can however achieve a quality improvement in his part of the project, provided that both agents agree to coordinate in implementing his high-quality knowledge input. At date 2, the labor market updates its beliefs based on the observed quality of implemented inputs, and determines the agents' earnings: $E\left[\theta_{i} \mid\right.$ first-period outcome $]$.

\subsection{Individual records}

Consider first the scenario where the market is able to inspect the quality of each agent's implemented input $x_{i}$ - referred to in the following as a situation with individual records. If both agents have high-quality knowledge inputs $\left(k_{i}=H_{i}, i=1,2\right)$, clearly, they will agree to coordinate: this way the market observes a profile of implemented inputs $\left(H_{1}, H_{2}\right)$ and knows

that each agent is talented $\left(\theta_{i}=\theta^{H}\right)$, which guarantees high future earnings for both. If both agents have low-quality knowledge inputs $\left(k_{i}=L_{i}, i=1,2\right)$, they cannot improve the product or process along any dimension, and the project outcome is a profile of implemented inputs $\left(L_{1}, L_{2}\right)$.

Let us turn to the case where only one agent has a high-quality knowledge input. Without loss of generality, assume it is agent 1 . The product or process cannot be improved along the dimension for which agent 2 is responsible because he only has a low-quality knowledge input, so the implemented input $x_{2}=L_{2}$ for sure. Thus coordination does not help agent 2 to gain anything for his own labor-market reputation.

What if the market is pessimistic and does not expect that an agent coordinates in such a situation? This would mean that the observed input qualities then are $\left(L_{1}, L_{2}\right)$ - the same as when both agents have low ability. The market takes this into account when forming beliefs 
about an agent after seeing a project outcome $\left(L_{1}, L_{2}\right)$ : with probability $(1-\alpha)^{2}$ the outcome arose because both agents lack talent (so a given agent's ability is $\theta^{L}$ ); whereas with probability $2 \alpha(1-\alpha)$ it arose because only one of the agents has a high-quality input but cannot show this for lack of coordination with his project partner (so a given agent's expected ability is $\left.\left(\theta^{L}+\theta^{H}\right) / 2\right)$. According to Bayes' rule, the expected ability for agent $i=1,2$ following project outcome $\left(L_{1}, L_{2}\right)$ hence is

$$
E\left[\theta_{i} \mid L_{1}, L_{2}\right]=\theta^{L}+\frac{\alpha}{1+\alpha}\left(\theta^{H}-\theta^{L}\right)
$$

This implies that agent 2 actually is strictly better off by not coordinating - confirming the market's pessimism. Suppose he did coordinate. Then the project outcome $\left(H_{1}, L_{2}\right)$ would reveal that coordination indeed occurred, leaving the market to conclude that the agent's low input quality stems from a lack of talent, so $E\left[\theta_{2} \mid H_{1}, L_{2}\right]=\theta^{L}<E\left[\theta_{2} \mid L_{1}, L_{2}\right]$. In other words, not coordinating with his more able project partner allows agent 2 to create a 'smoke screen' of collective mediocrity that masks his own inability to develop a high-quality knowledge input. This strategy is successful in equilibrium: with a project outcome $\left(L_{1}, L_{2}\right)$ the market cannot disentangle the possible causes, and therefore factors in for both agents the possibility that they might be talented but unable to show this for lack of coordination with a less able project partner $5^{5}$ To summarize, in such a smoke-screen equilibrium either both agents implement high-quality inputs or none of them does.

There is, of course, the alternative that the market optimistically thinks that an agent will always agree to coordinate when he is indifferent between coordinating and not coordinating. In this case we would have $E\left[\theta_{2} \mid H_{1}, L_{2}\right]=E\left[\theta_{2} \mid L_{1}, L_{2}\right]=\theta^{L}$ and coordination would indeed be a best response (given our assumption that coordination is costless). This 'coordination equilibrium' is however is not robust: ${ }^{6}$ Suppose there is a small probability that a low-ability agent does not coordinate with a more able project partner (this is a best response for him in any case). This implies that there is some chance of reaching the outcome $\left(L_{1}, L_{2}\right)$ even if one of the agents has a high-quality knowledge input (because of a tremble in the coordination decision). So the outcome $\left(L_{1}, L_{2}\right)$ still leaves open the possibility that agent $i=1,2$ is talented, whereas the outcome $\left(L_{i}, H_{-i}\right)$ reveals that agent $i$ lacks talent $]^{7}$ Hence, $E\left[\theta_{i} \mid L_{i}, H_{-i}\right]<E\left[\theta_{i} \mid L_{1}, L_{2}\right]$,

\footnotetext{
${ }^{5}$ Even if the market can distinguish situations where coordination occurred and where not, the 'smoke-screen' effect persists, as we show in Appendix C

${ }^{6}$ An alternative way to see why the 'coordination equilibrium' is not robust, is to assume that coordination entails a positive but arbitrarily small utility cost. This breaks the tie between coordinating or not when an agent has a low-quality input and makes coordination failure the only possible equilibrium outcome.

${ }^{7}$ Bayes' rule pins down beliefs because the information sets $\left(L_{1}, L_{2}\right)$ and $\left(L_{i}, H_{-i}\right)$ both are reached with positive probability.
} 
making coordination failure strictly optimal for an agent with knowledge input $L_{i}$. Proposition 1 below captures this formally by applying Selten's (1975) trembling-hand perfection criterion.

\subsection{Team record}

Suppose now that the project is organized instead as team production, and provides only a joint performance measure that does not allow attributing inputs to the individual team members. To reflect that the market only observes the team record, i.e. an anonymous profile of input qualities, we drop the subscripts from the input profile. That is, the market observes $(L, H)$ both if $\left(L_{1}, H_{2}\right)$ or $\left(H_{1}, L_{2}\right)$. Hence, both agents in a team share the same reputation, which is the key difference from the individual-records setting. Clearly, this does not change anything if both agents have high-quality knowledge inputs - they will coordinate and reveal that they both are talented: $E\left[\theta_{i} \mid H, H\right]=\theta^{H}$. The incentives to coordinate however change if the team can implement only one high-quality input. Now the agents have a common interest in increasing the perceived average ability level for the team, so coordination strictly pays off for both agents: the reputation that the team member with the (now anonymous) low-quality knowledge input achieves from coordination,

$$
E\left[\theta_{i} \mid L, H\right]=\theta^{L}+\frac{1}{2}\left(\theta^{H}-\theta^{L}\right)
$$

exceeds that arising when no high-quality inputs are implemented, $E\left[\theta_{i} \mid L, L\right]=\theta^{L}$. This outcome is indeed the only possible equilibrium. Why can a smoke-screen equilibrium as above not exist? Even if the market expected coordination failure, i.e. attributed in case of profile $(L, L)$ to each agent the same reputation as in (1), the team member with the low-quality knowledge input would be strictly better off coordinating with his more able colleague 8

$$
E\left[\theta_{i} \mid L, H\right]=\theta^{L}+\frac{1}{2}\left(\theta^{H}-\theta^{L}\right)>\theta^{L}+\frac{\alpha}{1+\alpha}\left(\theta^{H}-\theta^{L}\right) .
$$

We summarize our findings in the following result.

\section{Proposition 1 (The 'bare-bones' career concerns setting)}

With individual records, there is a unique trembling-hand perfect Nash equilibrium in which coordination fails unless both agents have high-quality knowledge inputs (smoke-screen equilibrium). With a team record, there is a unique trembling-hand perfect Nash equilibrium in which agents always coordinate to implement high-quality knowledge inputs.

It turns out that the driving forces underlying the result do not hinge on fine modeling details. The result extends to settings where there are more than two possible output levels (Appendix

\footnotetext{
${ }^{8} 1 / 2>\alpha /(1+\alpha)$ because $\alpha<1$.
} 
B), the market can observe in addition to the implemented inputs a signal whether or not coordination occurred (Appendix C), the market has asymmetric priors about the agents' abilities (Appendix D), and where implemented inputs are only observed if the project turns out to be successful (Appendix E).

Despite its simplicity, the above setting offers an important lesson: career concerns can have a detrimental effect on cooperation. If implemented inputs in a project can be closely associated with an individual, he may influence the project outcome to hide own shortcomings. By not coordinating with a more able colleague, an agent can impose an informational externality create a 'smoke screen' - behind which he can hide the lacking quality of his own project input. Interestingly, this sort of behavior is in line with an often expressed feeling that "it is better that everyone is in the same boat with me than that I stand in the shadow of the successes of others". While rivalries, jealousy and competition among peers may often be the cause, our setup shows that one needs to be cautious even if these elements are absent. Put differently, even if an individual does not care about the failure or success of his colleagues per se, he may still gain from influencing the outcomes of his colleagues to change the information content of performance measures that others use to evaluate him.

Team production removes such reputational conflicts of interest. Because it creates an anonymous record of inputs, it aligns the parties' interests in increasing the average reputation for the team. Indeed the role of teams in enhancing cooperation among the members of an organization is often viewed by economists, organizational psychologists as well as management and human resource scholars as one of the main reasons why firms rely on them rather than on structures that lead to individually attributable performance measures (e.g. Wageman 1995, Che and Yoo 2001, Hayton 2005). But reduced transparency about individuals' inputs also creates problems. Because rewards in a team accrue to all members, an individual can free-ride on his team mates' effort. This makes it more difficult to provide incentives for effort at the stage of developing knowledge inputs. We turn to this issue in the next section.

\section{Effort, coordination \& explicit incentives}

The success of an organization depends on its ability to foster the coordination needed to turn good ideas into new or improved products and services. But good ideas have to be developed in the first place, which requires that employees exert effort. What features should the humanresource system of an organization have to motivate both the creation and implementation of knowledge inputs? The previous section suggests that a close link between individual project 
members and their contributions to the implemented project may be problematic, and that team production may facilitate the implementation of knowledge inputs. However, when it comes to incentives for effort in developing knowledge inputs, teams suffer from the well known free-rider problem (Alchian and Demsetz 1972, Holmström 1982). To analyze how a firm optimally takes into account these conflicting forces when designing its human-resource system we now enrich the two-period, two-agent setting from the previous section.

\subsection{The model}

AgEnts. In the first period, the principal ('she') hires two ex ante identical risk neutral agents ('he') $i=1,2$ to work on a project. Agents are protected by limited liability and have an outside option with life-time expected utility normalized to 0 . The ability of an agent, $\theta_{i} \in[0,1]$, is initially unknown to both the principal and the agents. The common prior has density $f\left(\theta_{i}\right)$ with mean $\bar{\theta} \equiv E\left[\theta_{i}\right]$ and variance $\sigma^{2} \equiv \operatorname{Var}\left[\theta_{i}\right]$. In the second period, each agent has access to a labor market for experienced workers. There the principal and $n>2$ other potential employers simultaneously bid a wage for the services of each agent (see below).

Technology. The project in the first-period requires agents to develop knowledge inputs, and coordinate with each other to implement these. The knowledge input of an agent can be of high quality $\left(k_{i}=H_{i}\right)$ or low quality $\left(k_{i}=L_{i}\right)$. It takes both (unobservable) effort and talent to develop high-quality knowledge inputs, and the more able the agent the higher the impact of his effort. To capture this notion that the ability $\theta_{i}$ of an agent and his effort $e \in\{0,1\}$ are complements, we assume that

$$
\operatorname{Prob}\left(k_{i}=H_{i}\right)=e \theta_{i}, \quad \operatorname{Prob}\left(k_{i}=L_{i}\right)=1-e \theta_{i} .
$$

Effort causes a utility $\operatorname{cost} c(e=1)=c>0$, whereas $c(e=0)=0$. As described in Section 3. project members have to adapt their respective inputs to the production process to be mutually compatible. When agents agree to coordinate, the implemented inputs achieve their full potential: $\left(x_{1}, x_{2}\right)=\left(k_{1}, k_{2}\right)$. Without such coordination, the implemented inputs of both agents are of low quality: $\left(x_{1}, x_{2}\right)=\left(L_{1}, L_{2}\right)$. The principal obtains revenue $v_{x_{1}, x_{2}}$ from the project at the end of the first period. It increases with the quality of implemented inputs: $v_{H H}>v_{H L}=v_{L H}>v_{L L}$.

The Human-RESOURCE POLICY. Human-resource practices include both the design of work processes and compensation procedures. The former determines what performance measures become available and how informative they are about employees' contributions (e.g. Dewatripont et al. 1999b, Ortega 2003, Jeon 1996, Bar-Isaac 2007). For example, processes cen- 
tered around individual task assignments may allow observing individual inputs to a completed project. In contrast, individual contributions are less transparent in a team-based organization that promotes autonomy and "empowers" team members. We capture this notion by assuming that the principal chooses an information regime when contracting with the agents. Under the individual-records (IR) regime, she adopts job structures that make it possible to attribute implemented inputs $x_{i}$ to individual project members. Under the team-record (TR) regime, the principal organizes production in teams, for which performance is measurable only in the form of an anonymous profile of implemented inputs $(x, x)$.

The principal's compensation contract has a fixed wage $w_{1}$ in the first period and a performance-contingent bonus $\tau$ (first period outcome) that can condition on implemented input qualities. As explained in Section 3 , because of the tacit nature of knowledge inputs it is prohibitively costly for the principal to verify the potential quality of agents' inputs. Agents are protected by limited liability and cannot commit to staying with the principal in the second period (because the law prohibits indentured labor).

The SECOND PERIOD. In the second period, agents have access to a labor market for experienced workers where the principal and $n>2$ other potential employers ('the market') simultaneously bid a wage for the services of each agent. If agent $i$ switches to a new employer, his output is worth $\theta_{i}$. If he remains with the principal, he produces $\theta_{i}+\kappa$, where $\kappa>0$ is firm-specific human capital accumulated during the first period. As a result, the principal always matches the competitors' bids and the agent earns a second-period wage of at least $E\left[\theta_{i} \mid\right.$ first-period outcome $] .9$ For simplicity there is no discounting. As is standard in a career concerns model, there is symmetric information between the different employers. That is, the market observes the principal's choice of contract and agents' first-period project outcome.

Timing And Information STRUCTURE. In the first period, the principal chooses an organizational structure (IR- or $T R$-regime) and offers the two agents a contract $\left\{w_{1}, \tau(\right.$ first-period outcome $\left.)\right\}$. In case either agent rejects it, the principal has zero profits and agents have a life-time utility of zero. If the contract is accepted by both agents, they engage in (unobservable) effort to develop inputs, and decide whether to coordinate with their project partner after (privately) learning about the quality of their knowledge input. Then the project outcome realizes and is observed by market participants. While the implemented input

\footnotetext{
${ }^{9}$ This reduced-form specification and the normalization of the second-period productivity to equal $\theta_{i}$ are adopted for analytical simplicity. It could be replaced by any setup where the agent's utility from a secondperiod contract is increasing in his expected type. This is, of course, the precondition for career concerns in the first period to have any meaning.
} 
qualities $\left(x_{1}, x_{2}\right)$ can be attributed to each individual agent under the individual-record $(I R)$ structure, only an anonymous profile of input qualities $(x, x)$ is observed under the team-record $(T R)$ structure ${ }^{10}$ In the second period, the principal matches competing bids from the labor market to retain agents and capture their firm specific human capital.

Additional assumptions. From the extant literature it is well known that the principal may adopt an interdependent compensation scheme or teams to foster cooperation if helping others is costly, or if there are complementarities between the two agents' activities (see Section 2). To bring out the distinctive features of our model we thus make the following assumptions:

Assumption 1 Coordination to implement high-quality knowledge inputs imposes no costs on agents. There are no production externalities between the two agent's activities other than the need for coordination: revenue increases by a constant amount $\Delta v \equiv 1$ for each implemented high-quality input, i.e. $v_{H H}-v_{H L}=v_{L H}-v_{L L}=\Delta v$.

The normalization $\Delta v \equiv 1$ is adopted to avoid notational clutter. To make the problem interesting, we assume that effort is efficient. Effort $(e=1)$ and subsequent coordination by agents leads to an increase in expected revenue per head from $v_{L L} / 2$ (for $\left.e=0\right)$ to

$$
\int_{0}^{1}\left[v_{L L} / 2+\theta \Delta v\right] f(\theta) d \theta=v_{L L} / 2+\bar{\theta}
$$

This therefore gives:

Assumption 2 Effort towards developing knowledge inputs is efficient: $c \leq \bar{\theta}$.

Moreover, we assume that there are sufficiently many vacant positions so that agents do not compete with each other in the second-period labor market. This rules out impediments to cooperation stemming from any form of competition between agents (e.g. Lazear 1989, Baliga and Sjöström 2001, Chen 2003). We solve for Perfect Bayesian Nash equilibria (e.g. Fudenberg and Tirole 1986).

Except for the first-period wage $w_{1}$, the earnings of an agent depend on the first-period outcome: he receives a performance-contingent bonus $\tau_{i}$ (first-period outcome $) \geq 0$; and in the second period the principal matches the market wage $E\left[\theta_{i} \mid\right.$ first-period outcome $]$ to retain the agent. To simplify formulas, we will treat both performance-contingent components as part of the second-period wage. This is without loss of generality (because the principal and agents

\footnotetext{
${ }^{10}$ That is, the $I R$-information set is $\left\{\left(L_{1}, L_{2}\right),\left(L_{1}, H_{2}\right),\left(H_{1}, L_{2}\right),\left(H_{1}, H_{2}\right)\right\}$ and the $T R$-information set is $\{(L, L),(L, H),(H, H)\}$, where $(L, H)=\left(L_{1}, H_{2}\right) \cap\left(H_{1}, L_{2}\right)$.
} 
share the same discount factor - normalized to one in our model), and allows us to analyze contracts in terms of anticipated second-period earnings: 11

$$
w_{2 i}(\text { first-period outcome })=\tau_{i}(\text { first-period outcome })+E\left[\theta_{i} \mid \text { first-period outcome }\right] .
$$

\subsection{Analysis}

To complement Section 3 - which isolated the impact of career concerns on voluntary coordination - we start off our analysis with a second benchmark case, which isolates the effect of career concerns on effort incentives (no-coordination-stage benchmark). We then put everything together and analyze contracting when production requires both effort to develop knowledge inputs and coordination between agents to implement high-quality inputs. Based on these findings we then, in a last step, characterize the optimal human resource policy.

\subsection{No-coordination-stage benchmark (NB)}

The no-coordination-stage benchmark (NB) looks at the hypothetical case where agents do not need to coordinate to implement high-quality inputs. It will help assess the impact that the need for (costless) coordination has on the human resource system. The absence of a coordination stage effectively turns the production setting into two single-agent moral hazard problems with independent realizations of uncertainty. The optimal contract uses an $I R$ regime and conditions payments only on an agent's own input quality. This avoids the freeriding problems that would arise with group incentives or when moving to team production (TR-regime) ${ }^{12}$

As we saw above, effort increases the expected revenue per head by $\bar{\theta}$. But an agent will only engage in (unobservable) effort if the anticipated second-period wages $w_{2}\left(x_{i}\right)=E\left[\theta_{i} \mid x_{i}\right]+\tau\left(x_{i}\right)$ satisfy his incentive constraint:

$$
\bar{\theta} w_{2}\left(H_{i}\right)+(1-\bar{\theta}) w_{2}\left(L_{i}\right)-c \geq w_{2}\left(L_{i}\right) \quad \Leftrightarrow \quad w_{2}\left(H_{i}\right)-w_{2}\left(L_{i}\right) \geq c / \bar{\theta} .
$$

The principal however only has partial control over the anticipated wages. Because the agent is free to move to another employer in the second period, the principal must match the agent's wage opportunities in the market for experienced workers. All the principal can do is contractually bind herself to 'top up' the second-period market wage with a performance-related bonus

\footnotetext{
${ }^{11}$ Another way to think of this is that the principal's contract fixes the intra-firm wage evolution to anticipate outside opportunities in the second period, i.e. it specifies directly $\left\{w_{1}, w_{2 i}\right.$ (first-period outcome $\left.)\right\}$.

${ }^{12}$ This is a standard result which - for reasons of brevity - we state without proof here as our later analysis will clearly show the driving forces.
} 
$\tau\left(x_{i}\right) \geq 0$ (the agent is protected by limited liability). So to create the wage spread required by the incentive constraint (6) as cheaply as possible, the principal keeps the anticipated wage $w_{2}\left(L_{i}\right)$ at the lowest possible level by committing not to pay more than is necessary to retain the agent in the second period. That is, $\tau\left(L_{i}\right)=0$ and

$$
w_{2}\left(L_{i}\right)=E\left[\theta_{i} \mid L_{i}\right]=\int_{0}^{1} \theta f\left(\theta \mid L_{i}\right) d \theta=\int_{0}^{1} \frac{\theta(1-\theta) f(\theta)}{1-\bar{\theta}} d \theta=\bar{\theta}-\frac{\sigma^{2}}{1-\bar{\theta}} .
$$

If the agent develops and implements a high-quality input, he increases his market value to

$$
E\left[\theta_{i} \mid H_{i}\right]=\int_{0}^{1} \theta f\left(\theta \mid H_{i}\right) d \theta=\int_{0}^{1} \frac{\theta^{2} f(\theta)}{\bar{\theta}} d \theta=\bar{\theta}+\frac{\sigma^{2}}{\bar{\theta}} .
$$

Reputational incentives arise because $E\left[\theta_{i} \mid H_{i}\right]>E\left[\theta_{i} \mid L_{i}\right]$. Taking these into account, the agent's incentive constraint (6) and limited liability imply that

$$
\tau\left(H_{i}\right)=\max \left\{\frac{c}{\bar{\theta}}-\left(E\left[\theta_{i} \mid H_{i}\right]-E\left[\theta_{i} \mid L_{i}\right]\right), 0\right\}=\max \left\{\frac{c}{\bar{\theta}}-\frac{\sigma^{2}}{\bar{\theta}(1-\bar{\theta})}, 0\right\} .
$$

Overall, to implement effort and retain the agent in the second period the principal's contract has to lead to second-period wages $w_{2}\left(L_{i}\right)=E\left[\theta_{i} \mid L_{i}\right]$ and

$$
w_{2}\left(H_{i}\right)=E\left[\theta_{i} \mid H_{i}\right]+\tau\left(H_{i}\right)=\max \left\{\frac{c}{\bar{\theta}}+E\left[\theta_{i} \mid L_{i}\right], E\left[\theta_{i} \mid H_{i}\right]\right\} .
$$

If the required bonus for a high-quality input $\left(\tau\left(H_{i}\right)\right)$ is zero, this means that career concerns alone push the agent to exert effort. With the anticipated second-period wages in place, we now turn to the agent's participation constraint $w_{1}+\int_{0}^{1}\left[\theta w_{2}\left(H_{i}\right)+(1-\theta) w_{2}\left(L_{i}\right)\right] f(\theta) d \theta-c \geq 0$,

$$
\Leftrightarrow w_{1}+\int_{0}^{1}\left[\theta \tau\left(H_{i}\right)+\theta E\left[\theta_{i} \mid H_{i}\right]+(1-\theta) E\left[\theta_{i} \mid L_{i}\right]\right] f(\theta) d \theta=w_{1}+\bar{\theta} \tau\left(H_{i}\right)+\bar{\theta} \geq c .
$$

The last part reflects the martingale property of beliefs: $E\left[E\left[\theta \mid x_{i}\right]\right]=\bar{\theta}$. Because the agent is protected by limited liability, Assumption 2 implies that $w_{1}=0$. The agent has a limited liability rent.

What is the cost of implementing first-period effort? Whether the agent puts in effort or not, the principal will at least match the outside offers in the second-period labor market: retaining the agent allows capturing the return to firm-specific human capital, $\kappa>0$. So the extra cost of getting the agent to work stems only from the bonus $\tau\left(H_{i}\right)$ that the principal has to pay on top of the agent's market value when his implemented input has high quality $\left(x_{i}=H_{i}\right)$. So the effort implementation cost per head is simply the amount of bonus payments she expects to disburse to an agent:

$$
E C^{N B}=\int_{0}^{1}\left[\theta \tau\left(H_{i}\right)\right] f(\theta) d \theta=\max \left\{c-\frac{\sigma^{2}}{1-\bar{\theta}}, 0\right\}
$$

\footnotetext{
${ }^{13}$ Note that $w_{2}\left(L_{i}\right) \geq 0$ because $E\left[\theta_{i} \mid L_{i}\right]$ is in the support $[0,1]$ of $\theta$, implying the following implicit constraint on the parameter space: $\sigma^{2} \leq \bar{\theta}(1-\bar{\theta})$. Another way to see this: $\operatorname{Var}[\theta]=E\left[\theta^{2}\right]-\bar{\theta}^{2} \leq \bar{\theta}-\bar{\theta}^{2}$ because $0 \leq \theta \leq 1$.
} 
Assumption 2 implies that it indeed pays off for the principal to implement effort because the expected gain in revenue per head $\bar{\theta} \geq c>E C^{N B}$. We summarize this in the following result.

\section{Lemma 1 (No-coordination-stage benchmark)}

In the no-coordination-stage benchmark, where an agent can implement a high-quality input on his own, incentives based on individual performance (IR-regime) are optimal, and the effort implementation cost per head is:

$$
E C^{N B}=\left\{\begin{array}{lll}
c-\frac{\sigma^{2}}{1-\bar{\theta}} & \text { if } & \sigma^{2} \leq(1-\bar{\theta}) c \\
0 & \text { otherwise }
\end{array}\right.
$$

The more uncertainty there is about the ability of an agent (higher $\sigma^{2}$ ), the more the market learns about an agent from observing the first-period outcome. This, in turn, translates into a stronger desire for the agent to exert effort to influence his reputation and lowers the effort implementation cost. The no-coordination-stage benchmark case thus shows that the presence of career concerns itself does not create problems for effort incentives. To the contrary, career concerns are 'good' because they motivate the agent to put effort into developing knowledge inputs. How does the picture change when we add the coordination stage? The next section addresses this.

\subsection{Incentives based on own individual performance only}

The individual-records $(I R)$ regime in our main model differs from the no-coordination-stage benchmark in only one aspect: agents need to coordinate to implement high-quality knowledge inputs. This difference may seem innocuous given our assumption that coordination is without cost to the agents. Therefore, let us investigate what happens if the principal naïvely follows the policy appropriate for the no-coordination-stage benchmark, to base incentives only on the agent's own performance.

In this case there is the 'carrot' of topping up the market wage if a high-quality knowledge input by the agent is implemented $\left(w_{2 i}\left(H_{i}, \cdot\right) \geq E\left[\theta_{i} \mid H_{i}, \cdot\right]\right)$, and the 'stick' of not paying more than necessary to retain the agent in the second period if his implemented input is of low quality $\left(w_{2 i}\left(L_{i}, \cdot\right)=E\left[\theta_{i} \mid L_{i}, \cdot\right]\right)$. Solving backwards, consider the situation in which agents find themselves after they have developed their knowledge inputs. Faced with the above type of contract, an agent who only has a low-quality knowledge input can gain nothing from coordinating with his project partner because this reveals his lack of a high-quality knowledge 
input:

$$
E\left[\theta_{i} \mid L_{i}, H_{-i}\right]=E\left[\theta_{i} \mid L_{i}\right]=\bar{\theta}-\frac{\sigma^{2}}{1-\bar{\theta}} .
$$

Along the lines of Section 3 , suppose that the market expects coordination failure $(\mathrm{CF})$ in such a situation. Applying Bayes' rule, the market wage when both implemented inputs are of low quality then is

$$
E\left[\theta_{i} \mid L_{1}, L_{2}\right]^{C F}=\frac{(1-\bar{\theta})^{2}}{1-\bar{\theta}^{2}} E\left[\theta_{i} \mid L_{i}\right]+\frac{2 \bar{\theta}(1-\bar{\theta})}{1-\bar{\theta}^{2}} \frac{\left(E\left[\theta_{i} \mid L_{i}\right]+E\left[\theta_{i} \mid H_{i}\right]\right)}{2}=\bar{\theta}-\frac{\bar{\theta}}{1-\bar{\theta}^{2}} \sigma^{2} .
$$

As $E\left[\theta_{i} \mid L_{1}, L_{2}\right]^{C F}>E\left[\theta_{i} \mid L_{i}, H_{-i}\right]$, not to coordinate is indeed a strict best response for an agent who has only a low-quality knowledge input - confirming the market's coordination failure expectation 14 The situation mirrors the smoke-screen equilibrium from Proposition 1. Again, the outcome where the market expects coordination to always occur is not robust. Indeed, it is easy to verify that Proposition 1 carries over to the coordination-stage continuation game that we are looking at here, where incentives are based on the agent's individual performance only: 15

\section{Corollary 1 (Incentives based on own individual performance only)}

Incentives based on an agent's own individual performance only lead to a 'smoke-screen continuation equilibrium', in which coordination fails unless both agents develop high-quality knowledge inputs.

The result shows that the need for coordination has a substantial effect on the production outcome - even though the coordinating actions themselves are without direct cost to the agents. As in Section 3 , individualized incentives leave scope for setting up a 'smoke screen' behind which an agent can hide his own deficiencies. In other words, agents exploit the informational externality that they can impose on the project partner whenever this brightens their own future career prospects. With individual incentive pay, it is better for an agent to have the project partner share the same fate than to stand in the shadow of his success. While career concerns are 'good' for effort incentives - as we have seen in the no-coordination-stage benchmark - they are 'bad' for coordination under individualized incentives and lead to lower expected revenue for the principal.

\subsection{Coordination-enhancing human-resource policies}

The benefit from a human-resource policy that prevents the kind of coordination failure that arises in continuation equilibria with individualized incentives when only one agent has access

\footnotetext{
${ }^{14}$ Note that $E\left[\theta_{i} \mid L_{1}, L_{2}\right]^{C F}=\bar{\theta}-\frac{\bar{\theta}}{1+\bar{\theta}} \frac{\sigma^{2}}{1-\bar{\theta}}$.

${ }^{15}$ Simply substitute $\theta^{H}=E\left[\theta_{i} \mid H_{i}\right], \theta^{L}=E\left[\theta_{i} \mid L_{i}\right]$ and $\alpha=\bar{\theta}$ into the equations of Section 3
} 
to a high-quality knowledge input is that expected revenue increases by $2 \bar{\theta}(1-\bar{\theta})$. We now turn to the additional costs of such a policy, examining first group-based incentives under the $I R$-regime, and then team production.

\subsubsection{Group-based incentives (IR-regime)}

The gap in anticipated second-period wages $w_{2 i}\left(L_{i}, H_{-i}\right)$ and $w_{2 i}\left(L_{1}, L_{2}\right)$ is what causes coordination failure under individualized incentives. To close this gap, the principal can include in her contract a provision that offsets the reputational gain $E\left[\theta_{i} \mid L_{1}, L_{2}\right]^{C F}-E\left[\theta_{i} \mid L_{i}, H_{-i}\right]$ that an agent derives by not coordinating with a more successful project partner in the 'smoke-screen continuation equilibrium' from Corollary 1. If the contract includes such a group-performance component

$$
\tau_{i}\left(L_{i}, H_{-i}\right)=E\left[\theta_{i} \mid L_{1}, L_{2}\right]^{C F}-E\left[\theta_{i} \mid L_{i}, H_{-i}\right]=\frac{\sigma^{2}}{1-\bar{\theta}^{2}}
$$

coordination indeed becomes a best response for an agent who is less successful than his colleague. This is true even if the market expected coordination failure $(\mathrm{CF})$ for this case. The contractual provision $\tau_{i}\left(L_{i}, H_{-i}\right)$ therefore leads to a unique ${ }^{16}$ continuation equilibrium, in which agents always coordinate when there is a high-quality knowledge input available and, consistent with this, the market expects no coordination failure on the equilibrium path:

$$
E\left[\theta_{i} \mid L_{1}, L_{2}\right]=E\left[\theta_{i} \mid L_{i}, H_{-i}\right]=\bar{\theta}-\frac{\sigma^{2}}{1-\bar{\theta}}
$$

It turns out that under certain circumstances contracts with group-based incentives $0<$ $\tau_{i}\left(L_{i}, H_{-i}\right)<\frac{\sigma^{2}}{1-\theta^{2}}$ can also prevent coordination failure. Namely, if the market then believes that coordination will occur, coordination is indeed always a strict best response. There however is an alternative continuation equilibrium where the market has coordination failure expectations, and then not coordinating is a strict best response for an agent who has not developed a high-quality knowledge input. While this multiplicity of continuation equilibria is interesting, it will play no role in our main results as we explain below. We therefore relegate the details to Appendix $\mathrm{A}$ and summarize our findings findings in the following result.

\footnotetext{
${ }^{16}$ To be precise, uniqueness obtains if the agent has a strict best response, i.e. $\tau_{i}\left(L_{i}, H_{-i}\right)>E\left[\theta_{i} \mid L_{1}, L_{2}\right]^{C F}-$ $E\left[\theta_{i} \mid L_{i}, H_{-i}\right]$. Instead of imposing a finite minimum compensation increment (which would make derivations extremely messy with no added economic insight) we adopt the usual convention of breaking the tie to achieve existence of equilibrium in the overall game.
} 


\section{Lemma 2 (Group-based incentives ( $I R$-regime) continuation equilibria)}

In the continuation game that follows the contract offer stage,

- a contract with $\tau_{i}\left(L_{i}, H_{-i}\right)=\frac{\sigma^{2}}{1-\bar{\theta}^{2}}$ induces a unique continuation equilibrium, where agents always coordinate to implement high-quality knowledge inputs;

- for each contract with $\tau_{i}\left(L_{i}, H_{-i}\right) \in\left(0, \frac{\sigma^{2}}{1-\bar{\theta}^{2}}\right)$ there exist two continuation equilibria:

i) a 'smoke-screen continuation equilibrium' where coordination fails unless both agents develop high-quality knowledge inputs;

ii) an equilibrium where agents always coordinate to implement high-quality knowledge inputs.

This result allows us to characterize for the possible continuation equilibria the cost per agent of implementing effort and always achieving coordination under group-based incentives. If $\tau_{i}\left(L_{i}, H_{-i}\right) \rightarrow 0$ suffices to convince the market not to expect coordination failure, implementation costs reach their lower bound - which corresponds to $E C^{N B}$ from the no-coordinationstage benchmark (NB) in Lemma1. Conversely, implementation costs reach their upper bound in the continuation equilibrium induced by $\tau_{i}\left(L_{i}, H_{-i}\right)=\frac{\sigma^{2}}{1-\bar{\theta}^{2}}$. This leads to the following result:

\section{Lemma 3 (Group-based incentives (IR-regime))}

To prevent coordination failure in the continuation game under the IR-regime, the contract must include a group-performance component $\tau_{i}\left(L_{i}, H_{-i}\right)>0$. The expected cost per head of implementing effort and preventing coordination failure with group-based incentives is bounded below by the implementation cost under the no-coordination-stage benchmark EC ${ }^{N B}$ (stated in Lemma 1) and above by $\overline{E C}^{I R}: E C^{N B}<E C^{I R} \leq \overline{E C}^{I R}$, where

$$
\overline{E C}^{I R}=\left\{\begin{array}{lll}
c-\frac{\sigma^{2}}{1-\bar{\theta}^{2}} & \text { if } & \sigma^{2} \leq \frac{1-\bar{\theta}^{2}}{1+\bar{\theta}(1-\bar{\theta})} c \\
\frac{\bar{\theta}}{1+\bar{\theta}} \sigma^{2} & \text { otherwise. }
\end{array}\right.
$$

Two things about the wage structure are striking. First, an agent receives a sizable reward for the successful implementation of a high-quality input by his project partner, even though his direct cost of coordination is zero: $w_{2 i}\left(L_{i}, H_{-i}\right)=w_{2 i}\left(L_{1}, L_{2}\right)+\tau_{i}\left(L_{i}, H_{-i}\right)$. This shows how group-based incentives may arise also in a setting where it there is no need to compensate for costly helping activities.

Second, the group-performance pay component $\tau_{i}\left(L_{i}, H_{-i}\right)$ does not capture the entire cost of achieving coordination. The reason is that this pay component itself introduces the opportunity to free-ride on the effort of the project partner and makes shirking more attractive. An 
agent who shirks would still get $\tau_{i}\left(L_{i}, H_{-i}\right)$ in addition to his market value of $E\left[\theta_{i} \mid L_{i}\right]$ whenever the project partner develops a high-quality knowledge input. In contrast, if no coordination stage were necessary - as in the no-coordination-stage benchmark - a shirking agent would never earn more than $E\left[\theta_{i} \mid L_{i}\right]$. To prevent shirking therefore requires a higher anticipated wage for the case that an agent has himself a successfully implemented high-quality input than the required wage under the no-coordination-stage benchmark (NB). Overall we therefore have: $w_{2 i}\left(H_{i}, \cdot\right) \geq w_{2}^{N B}\left(H_{i}\right)>w_{2 i}\left(L_{i}, H_{-i}\right)>w_{2 i}\left(L_{1}, L_{2}\right)=w_{2}^{N B}\left(L_{i}\right){ }^{17}$

While there are multiple continuation equilibria, it turns out that we can nevertheless arrive at a precise prediction about the optimal human-resource policy. The reason is as follows. In an equilibrium of the overall contracting game, the choice of compensation contract depends on how the resulting profit compares with the alternative continuation profits from other policies. The market (out-of-equilibrium) beliefs determine for each possible $I R$-regime contract with $\tau_{i}\left(L_{i}, H_{-i}\right) \in\left(0, \frac{\sigma^{2}}{1-\bar{\theta}^{2}}\right)$ which continuation equilibrium would be played - the one with or without coordination failure. In contrast, the continuation equilibrium induced by $\tau_{i}\left(L_{i}, H_{-i}\right)=\frac{\sigma^{2}}{1-\theta^{2}}$ is unique and therefore 'available' to the principal in any equilibrium of the overall contracting game. So if group-based incentives pay off in this case where they are at their most expensive $\left(E C^{I R}=\overline{E C}^{I R}\right)$, then they must be part of the optimal human-resource policy in any equilibrium of the overall contracting game. It turns out that this argument will sharply pin down (in Proposition 3) when group-based incentives are and when they are not optimal - so that the multiplicity of continuation equilibria will actually play no role in our main results.

\subsubsection{Team production (TR-regime)}

To foster coordination, an alternative human-resource strategy is to revert to a team production structure - this was one lesson from Section 3. Indeed, under the team-record (TR) regime agents always have a shared interest in implementing high-quality knowledge inputs: anything that helps push up the average reputation of the team is good for the individual agent as well. What does the $T R$-contract structure look like? It offers a bonus $\tau_{i}(H, H) \geq 0$ and the principal simply matches the market wage otherwise. The reason is that whenever two high-quality knowledge inputs are implemented the principal knows for sure that the agents exerted effort. All other output states could potentially also be reached if either one of the agents shirked, because input quality is not individually attributable. Specifically, the principal min-

\footnotetext{
${ }^{17} w_{2}^{N B}\left(H_{i}\right) \geq E\left[\theta_{i} \mid H_{i}, \cdot\right]>E^{C F}\left[\theta_{i} \mid L_{1}, L_{2}\right] \geq E\left[\theta_{i} \mid L_{1}, L_{2}\right]+\tau_{i}\left(L_{i}, H_{-i}\right)=w_{2 i}\left(L_{i}, H_{-i}\right)$ [the last inequality follows from 15 and Lemma 2 .
} 
imizes the cost of providing incentives by concentrating rewards in the output state $(H, H)$ as this is most informative about the agent's effort. Or, put more formally, the likelihood ratio $\operatorname{prob}\left(x, x \mid\right.$ effort $\left._{i}\right) / \operatorname{prob}\left(x, x \mid\right.$ no effort $\left._{i}\right)$ is maximized in state $(x, x)=(H, H){ }^{18}$ Hence, $w_{2 i}(H, H)=\tau_{i}(H, H)+E\left[\theta_{i} \mid H, H\right]$, and for the other states $(x, x) \in\{(L, L),(L, H)\}$ we simply have $w_{2 i}(x, x)=E\left[\theta_{i} \mid x, x\right]$. The incentive constraint thus becomes

$$
\begin{gathered}
\bar{\theta}^{2}\left(\tau_{i}(H, H)+E\left[\theta_{i} \mid H, H\right]\right)+2 \bar{\theta}(1-\bar{\theta}) E\left[\theta_{i} \mid H, L\right]+(1-\bar{\theta})^{2} E\left[\theta_{i} \mid L, L\right]-c \\
\geq \bar{\theta} E\left[\theta_{i} \mid H, L\right]+(1-\bar{\theta}) E\left[\theta_{i} \mid L, L\right] .
\end{gathered}
$$

This leads to the per capita implementation cost under team production given in the following result.

\section{Lemma 4 (Team production (TR-regime))}

The expected cost per head of implementing effort and preventing coordination failure with team production (TR-regime) is

$$
E C^{T R}=\left\{\begin{array}{lll}
c-\frac{\sigma^{2}}{2(1-\bar{\theta})} & \text { if } & \sigma^{2} \leq 2(1-\bar{\theta}) c \\
0 & \text { otherwise }
\end{array}\right.
$$

While the $T R$-regime always achieves voluntary coordination because team members' inputs are not individually attributable, this very fact makes it harder to provide agents with incentives to exert effort in developing knowledge inputs. The well known moral hazard in teams problem arises (Holmström 1982): an agent who shirks can still benefit from his team mate's effort because $w_{2 i}(L, H)=E\left[\theta_{i} \mid L, H\right]>w_{2 i}(L, L)=E\left[\theta_{i} \mid L, L\right]$. Therefore, as is easy to verify, the per capita implementation cost is higher than in the no-coordination-stage benchmark (NB): $E C^{N B}<E C^{T R}$.

\subsection{Optimal human-resource policies}

Our results thus far tell us about the costs and benefits of preventing coordination failure. The benefit is that these policies avoid the expected loss in revenue $2 \bar{\theta}(1-\bar{\theta})$ that occurs under a contract that bases rewards on an agent's own performance only. Preventing coordination failure however creates a free-riding opportunity that raises the cost of providing effort incentives. So does it actually pay to put in place such a cooperation-enhancing human-resource policy, and if it does, under what conditions? It turns out that the answer is sharp:

\footnotetext{
${ }^{18}$ See Demougin and Fluet (1998) for a detailed discussion of ranking different information systems based on likelihood ratios in moral hazard problems with risk neutral agents that are protected by limited liability. For a more general discussion see e.g. Laffont and Martimort (2002).
} 


\section{Proposition 2 (Optimality of group-based incentives or team production)}

It is optimal to foster coordination, using either group-based incentives (IR-regime) or team production (TR-regime). Incentives tied exclusively to an agent's own individual performance are never optimal.

The proof in Appendix $\mathrm{A}$ shows that the expected profit under team production is always higher than if the contract offers incentives based on own individual performance only under the $I R$-regime. This leaves as sole alternative group-based incentives.

How does the contracting environment influence which specific human resource policy is optimal in our model? The principal achieves cooperation by rewarding an agent for coordinating with a more successful project partner. Under team production this reward arises from the increase in second-period wages caused by a high-quality input in the team's project, $E\left[\theta_{i} \mid L, H\right]-E\left[\theta_{i} \mid L, L\right]$. Under group-based incentives (IR-regime) the principal pays an explicit bonus $\tau_{i}\left(L_{i}, H_{-i}\right)$. Both types of rewards create an opportunity to free-ride, and thereby increase the implementation cost.

It turns out that group-based incentives leads to lower free-riding costs than team production (this is true for all cooperation-inducing continuation equilibria from Lemma 2).19 The advantage of team production however is that the joint-performance reward arises implicitly through the market wages, whereas under the $I R$-regime the principal has to pay out the group-based compensation component $\tau_{i}\left(L_{i}, H_{-i}\right)>0$ in addition to what is needed to retain the agent in the second period. So, intuitively, teams function well when the career opportunities in the second-period market offer sufficiently strong incentives for the agents to also overcome the free-riding problem in the team. When career concerns are less powerful, the principal needs to offer additional explicit incentives, and thus bears part of the effort implementation cost. In this case, group-based incentives are the more cost-effective way of inducing coordination. The next result formalizes the intuition.

\footnotetext{
${ }^{19}$ Intuitively, because $w_{2 i}^{T R}(L, L)=w_{2 i}^{I C}\left(L_{1}, L_{2}\right)$, the severity of the free-riding problem depends on what an agent who shirks earns when his colleague develops a high-quality knowledge input. Under the $I R$-regime, a shirking agent gains at most what he could get by not coordinating in a smoke-screen equilibrium: $\tau_{i}\left(L_{i}, H_{-i}\right) \leq$ $E\left[\theta_{i} \mid L_{1}, L_{2}\right]^{C F}-E\left[\theta_{i} \mid L_{i}\right]$. As, $w_{2 i}^{I R}\left(L_{i}, H_{-i}\right)=E\left[\theta_{i} \mid L_{i}\right]+\tau_{i}\left(L_{i}, H_{-i}\right)$ we have $w_{2 i}^{I R}\left(L_{i}, H_{-i}\right) \leq E\left[\theta_{i} \mid L_{1}, L_{2}\right]^{C F}$. But in a smoke-screen equilibrium the market factors in the possibility that both agents only have low-quality knowledge inputs, so $E\left[\theta_{i} \mid L_{1}, L_{2}\right]^{C F}<E\left[\theta_{i} \mid L, H\right]=w_{2 i}^{T R}(L, H)$.
} 


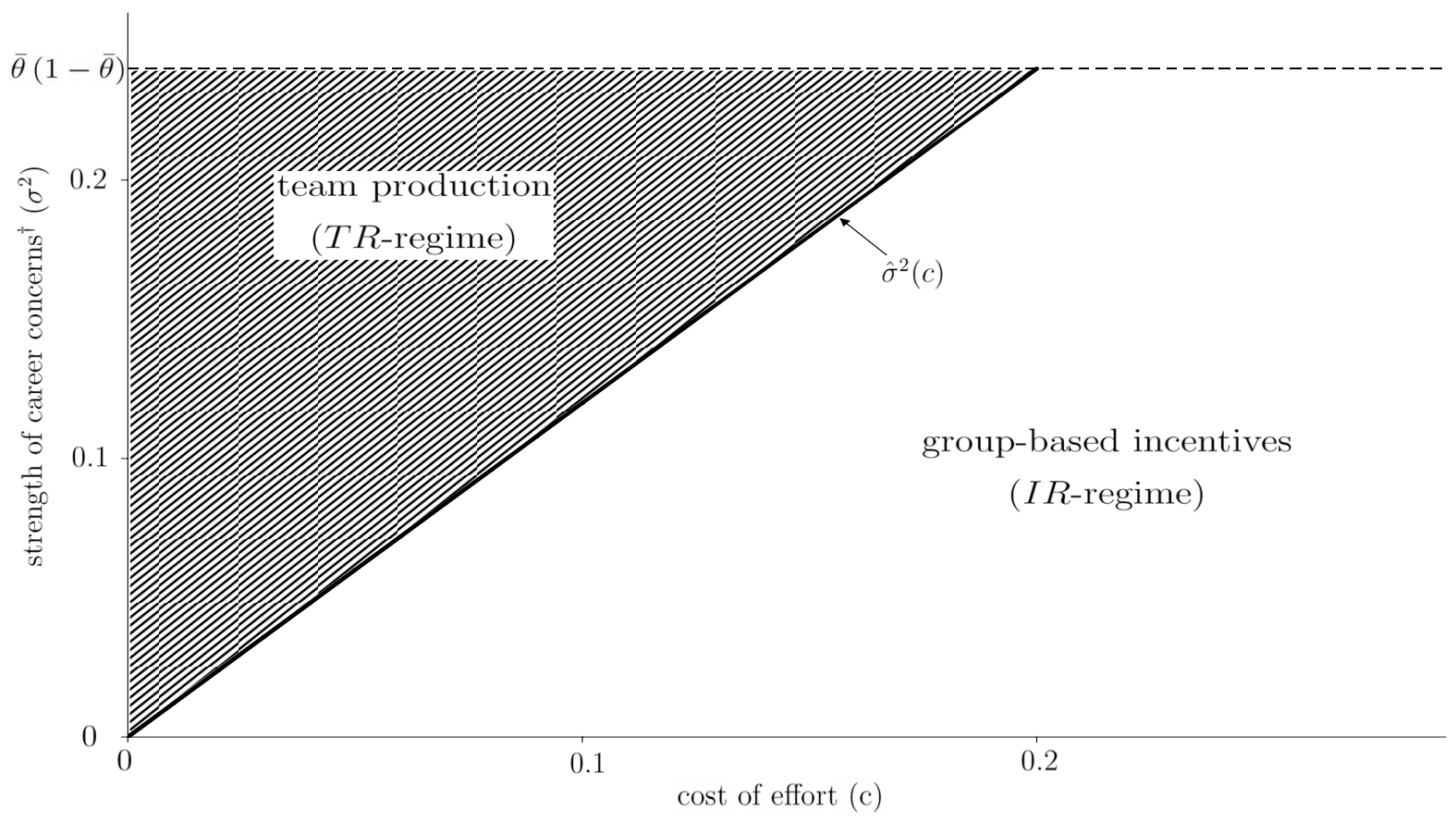

$\dagger$ The parameter restriction $\sigma^{2}<\bar{\theta}(1-\bar{\theta})$ is implicit in the model structure [see Section 4.3].

Figure 1: Optimal human-resource policy [parametric example with $\bar{\theta}=0.4$ ]

\section{Proposition 3 (Optimal human-resource policies)}

The principal organizes production under the IR-regime with group-based incentives if career concerns are relatively weak in relation to the effort cost $\left(\sigma^{2} \leq \hat{\sigma}^{2}(c)\right)$. If career concerns are relatively strong $\left(\sigma^{2}>\hat{\sigma}^{2}(c)\right)$, the TR-regime with team incentives is optimal, where

$$
\hat{\sigma}^{2}(c)=2(1-\bar{\theta}) c
$$

The proof in Appendix $\mathrm{A}$ consists of a comparison of implementation costs under the two regimes for varying strength of career concerns (measured by the parameter $\sigma^{2}$ ).

The result suggests that team production should emerge in situations where career concerns tend to be relatively important. Group-based incentives should dominate when career concerns play a lesser role. Figure 1 illustrates this with a parametric example. The vertical axis measures the strength of career concerns $\left(\sigma^{2}\right)$ and the horizontal axis the cost of effort $c$. Group-based incentives are optimal in the region below the cutoff $\hat{\sigma}^{2}(c)$, where career concerns are relatively weak in relation to the effort cost. Team production is optimal in the shaded region above $\hat{\sigma}^{2}(c)$, where career concerns are relatively strong. 


\section{Discussion and conclusion}

Group-based incentives and team production - the policies that are optimal in our model according to Proposition 2 - have become a staple in modern firms ${ }^{20}$ Such policies are optimal despite the lack of payoff externalities or costs for helping a co-worker in our model - factors that have previously been associated with group- or team-based incentives (e.g. Itoh 1991, Hemmer 1995).

What our model adds to the literature is the notion that joint production settings offer employees opportunities to impose informational externalities on the work outcomes. For this reason career concerns can have a distinct effect on employees' motivation i) to put effort into developing knowledge inputs; ii) to cooperate in implementing knowledge inputs. Our analysis shows that employees' concerns for their labor market reputation can both be 'good' (enhancing incentives for effort provision) and 'bad' (getting in the way of coordination). One role of cooperation-enhancing elements in the human-resource policy of a firm therefore is to deflect the detrimental effect that employees' career concerns could otherwise have on the production outcome. Together with the results in the literature this suggests that there is indeed a robust theoretical foundation for the philosophy of fostering cooperation that underlies human-resource policies in modern firms.

The comparative statics of our model in Proposition 3 shed light on a possible link between the growing importance of "empowered" teams in firms and changes in labor markets that have affected the strength of individuals' career concerns. Rapid technological progress increased the importance of "knowledge work" in the US and other advanced economies over the last three decades (e.g. Despres and Hiltrop 1995, OECD 1996, 2001, Foray 2004). The resulting shifts in labor demand 21 enhanced returns to skill, both linked to easily observed components (such as education and experience) as well as linked to measures of unobserved ability (e.g. Juhn, Murphy, and Pierce 1993, Murnane, Willett, and Levy 1995, Bartel and Sicherman 1999, Galor and Moav 2000, Bresnahan, Brynjolfsson, and Hitt 2002). In a parallel development, firms introduced innovative organizational practices and increasingly restructured production processes to rely on "empowered" teams. By the mid-1990s more than $60 \%$ of larger U.S. establishments had adopted teams and other "innovative workplace practices" according to the influential studies by Osterman $(1994,2000)$. For knowledge-intensive firms

\footnotetext{
${ }^{20}$ Around $70 \%$ of the Fortune 1000 companies had adopted work group or team incentives by 1993 according to surveys by the Center for Effective Organizations, University of Southern California reported in Lawler, Mohrman, and Ledford (1995). See also Ichniowski and Shaw (2003) and Boning, Ichniowski, and Shaw (2007).

${ }^{21}$ For a discussion of the controversial issues surrounding these changes in labor markets, see e.g. Card and DiNardo (2002) and Autor, Katz, and Kearney (2008).
} 
these developments are especially important, because their focus on innovation exposes them to the coordination and information sharing problems at the heart of our model (e.g. Despres and Hiltrop 1995, Mohrman, Cohen, and Mohrman 1995, Faraj and Sproull 2000, Paulus and Yang 2000, Lawler 2003). Proposition 3 predicts that knowledge-intensive firms should switch to team-based production when employees' work outcomes have a strong effect on their labor market opportunities - in line with the above trends. This result thus suggests the intriguing possibility of a connection between stronger career concerns that employees face because of changes in labor markets and shifts in human-resource policies in knowledge-intensive firms. An interesting avenue for future research is to explore empirically this link between human resource policies and labor market conditions.

\section{Appendix}

\section{A Proofs}

\section{Proof of Proposition 1 .}

The arguments in the main text derive the equilibria. What remains to be shown is that the smoke-screen equilibrium under the $I R$-regime is the unique trembling-hand perfect Nash equilibrium. Consider the alternative candidate equilibrium: the coordination equilibrium where team members always attempt to implement high-quality inputs. Suppose that trembles cause coordination to fail with probability $\xi>0$. The coordination equilibrium is a tremblinghand perfect Nash equilibrium only if we can show that it is the limit of a sequence of Nash equilibria indexed by $\xi$. Suppose, by way of contradiction, that some $\xi>0$ leads to a Nash equilibrium with no coordination failure. We now construct the corresponding market beliefs based on Bayes' rule, and show that for an agent who does not have a high-quality input it is a strict best reply not to coordinate, leading to a contradiction.

$$
\begin{aligned}
E\left[\theta_{i} \mid L_{1}, L_{2}\right] & =\frac{\operatorname{Prob}(x x=L L) \theta^{L}+\xi\left\{\operatorname{Prob}(x x=L H)\left(\theta^{L}+\theta^{H}\right) / 2+\operatorname{Prob}(x x=H H) \theta^{H}\right\}}{\operatorname{Prob}(x x=L L)+\xi[\operatorname{Prob}(x x=L H)+\operatorname{Prob}(x x=H H)]} \\
& =\frac{(1-\alpha)^{2} \theta^{L}+\xi\left\{2 \alpha(1-\alpha)\left(\theta^{L}+\theta^{H}\right) / 2+\alpha^{2} \theta^{H}\right\}}{(1-\alpha)^{2}+\xi \alpha(2-\alpha)} \\
& =\theta^{L}+\frac{\xi \alpha}{(1-\alpha)^{2}+\xi \alpha(2-\alpha)}\left(\theta^{H}-\theta^{L}\right)>E\left[\theta_{i} \mid L_{i}, H_{-i}\right]=\theta^{L} .
\end{aligned}
$$

The smoke-screen equilibrium is robust to small trembles in the players' coordination decision, as is easily verified.

\section{Proof of Lemma 2,}

The first part was shown in the main text. Clearly, it will never be optimal for the principal 
to offer a contract where she pays more than is needed to achieve coordination in any of the available continuation equilibria, so we can safely ignore the continuation equilibria with $\tau_{i}\left(L_{i}, H_{-i}\right)>\frac{\sigma^{2}}{1-\bar{\theta}^{2}}$.

Note that the principal could possibly sway the market to expect no coordination failure even if the contract only offered a smaller "compensation" $\tau_{i}\left(L_{i}, H_{-i}\right)>0$. In that case, the market wages would be $E\left[\theta_{i} \mid L_{i}, H_{-i}\right]=E\left[\theta_{i} \mid L_{1}, L_{2}\right]$; and $\tau_{i}\left(L_{i}, H_{-i}\right)>0$ would ensure that it is indeed a best response for the agents to coordinate. In other words, there is a continuum of continuation equilibria with $\tau_{i}\left(L_{i}, H_{-i}\right) \in\left(0, \frac{\sigma^{2}}{1-\theta^{2}}\right)$, where coordination failure does not arise. These alternative continuation equilibria however are not unique. For $\tau_{i}\left(L_{i}, H_{-i}\right) \in\left(0, \frac{\sigma^{2}}{1-\bar{\theta}^{2}}\right)$ the market may just as well expect coordination failure $(\mathrm{CF})$ to arise. The resulting secondperiod wage $E\left[\theta_{i} \mid L_{1}, L_{2}\right]^{C F}>E\left[\theta_{i} \mid L_{i}, H_{-i}\right]+\tau_{i}\left(L_{i}, H_{-i}\right)$ makes it a best response for an agent with a low-quality input not to coordinate, confirming the market belief.

\section{Proof of Lemma 3 .}

For $\tau_{i}\left(L_{i}, H_{-i}\right) \rightarrow 0$ the contract achieves the effort implementation cost of the nocoordination-stage benchmark in the limit because the free-riding problem disappears. The upper bound on implementation cost is achieved if the principal must offer $\tau_{i}\left(L_{i}, H_{-i}\right)=$ $\sigma^{2} /\left(1-\bar{\theta}^{2}\right)$ to move the market away from expecting coordination failure in the continuation game. Then an agent's expected payoff when not putting in effort is $\frac{\bar{\theta}}{1-\bar{\theta}^{2}} \sigma^{2}$ higher than the payoff from shirking in the no-coordination-stage benchmark setting. To quantify the impact this has on the implementation cost, plug $w_{2 i}\left(L_{i}, H_{-i}\right)=\tau_{i}\left(L_{i}, H_{-i}\right)+E\left[\theta_{i} \mid L_{i}, \cdot\right]$ and $w_{2 i}\left(L_{1}, L_{2}\right)=E\left[\theta_{i} \mid L_{i}, \cdot\right]$ into the agent's incentive constraint. The anticipated second-period wage following a successfully implemented high-quality input, $w_{2 i}\left(H_{i}, \cdot\right)$, hence has to satisfy ${ }^{22}$

$$
\bar{\theta} w_{2 i}\left(H_{i}, \cdot\right)+(1-\bar{\theta}) E\left[\theta_{i} \mid L_{i}, \cdot\right]+\bar{\theta}(1-\bar{\theta}) \frac{\sigma^{2}}{1-\bar{\theta}^{2}}-c \geq \frac{\bar{\theta}}{1-\bar{\theta}^{2}} \sigma^{2}+E\left[\theta_{i} \mid L_{i}, \cdot\right] .
$$

Together with limited liability this implies that,

$$
\begin{aligned}
w_{2 i}\left(H_{i}, \cdot\right) & =\max \left\{\frac{c}{\bar{\theta}}+E\left[\theta_{i} \mid L_{i}, \cdot\right]+\frac{\bar{\theta}}{1-\bar{\theta}^{2}} \sigma^{2}, E\left[\theta_{i} \mid H_{i}, \cdot\right]\right\} \\
& =\max \left\{\frac{c}{\bar{\theta}}+\bar{\theta}-\frac{\sigma^{2}}{1-\bar{\theta}^{2}}, E\left[\theta_{i} \mid H_{i}, \cdot\right]\right\} .
\end{aligned}
$$

Expressed in terms of bonus that the contract has to promise after a high-quality input is implemented we get:

$$
\tau_{i}\left(H_{i}, \cdot\right)=w_{2 i}\left(H_{i}, \cdot\right)-E\left[\theta_{i} \mid H_{i}, \cdot\right]=\max \left\{\frac{c}{\bar{\theta}}-\frac{1+\bar{\theta}(1-\bar{\theta})}{\bar{\theta}\left(1-\bar{\theta}^{2}\right)} \sigma^{2}, 0\right\} .
$$

\footnotetext{
${ }^{22}$ This wage structure is without loss of generality because the principal and agent are indifferent between payments following $\left(H_{1}, H_{2}\right)$ or following $\left(H_{i}, L_{-i}\right)$, or some combination of the two, as long as the they have the same expected value.
} 
From this we obtain the upper bound given in the result:

$$
\overline{E C}^{I R}=\bar{\theta} \tau_{i}\left(H_{i}, \cdot\right)+\bar{\theta}(1-\bar{\theta}) \tau_{i}\left(L_{i}, H_{-i}\right) .
$$

\section{Proof of Lemma 4 .}

The market wages in the second period are:

$$
\begin{gathered}
E\left[\theta_{i} \mid H, H\right]=\bar{\theta}+\frac{\sigma^{2}}{\theta}, \quad E\left[\theta_{i} \mid L, L\right]=\bar{\theta}-\frac{\sigma^{2}}{1-\theta}, \\
E\left[\theta_{i} \mid H, H\right]>E\left[\theta_{i} \mid L, H\right]=\frac{1}{2}\left(E\left[\theta_{i} \mid H, H\right]+E\left[\theta_{i} \mid L, L\right]\right)=\bar{\theta}+\frac{1-2 \bar{\theta}}{\theta(1-\theta)} \sigma^{2}>E\left[\theta_{i} \mid L, L\right] .
\end{gathered}
$$

With the incentive constraint (17) in the main text it follows that

$$
\tau_{i}(H, H)=\max \left\{\frac{c}{\bar{\theta}^{2}}-\frac{\sigma^{2}}{2 \bar{\theta}^{2}(1-\bar{\theta})}, 0\right\} .
$$

The result obtains because $E C^{T R}=\bar{\theta}^{2} \tau_{i}(H, H)$.

\section{Proof of Proposition 2,}

We start by deriving the contract when coordination failure is not prevented. As coordination occurs only if both agents develop high-quality knowledge inputs, the incentive constraint becomes

$$
\begin{aligned}
& \bar{\theta}^{2} w_{2 i}\left(H_{1}, H_{2}\right)+\left(1-\bar{\theta}^{2}\right) E\left[\theta_{i} \mid L_{1}, L_{2}\right]^{C F}-c \geq E\left[\theta_{i} \mid L_{1}, L_{2}\right]^{C F,} \\
\Leftrightarrow & w_{2 i}\left(H_{1}, H_{2}\right) \geq \frac{c}{\bar{\theta}^{2}}+E\left[\theta_{i} \mid L_{1}, L_{2}\right]^{C F} .
\end{aligned}
$$

Hence, the bonus after an implemented high-quality input has to be

$$
\tau_{i}\left(H_{1}, H_{2}\right) \equiv w_{2 i}\left(H_{1}, H_{2}\right)-E\left[\theta_{i} \mid H_{1}, H_{2}\right]=\max \left\{\frac{c}{\bar{\theta}^{2}}-\frac{\sigma^{2}}{\bar{\theta}\left(1-\bar{\theta}^{2}\right)}\right\} .
$$

This leads to expected cost per head of implementing effort

$$
E C^{C F}=\bar{\theta}^{2} \tau_{i}\left(H_{1}, H_{2}\right)=\left\{\begin{array}{lcc}
c-\frac{\bar{\theta}}{1-\bar{\theta}^{2}} \sigma^{2} & \text { if } & \sigma^{2} \leq \frac{1-\bar{\theta}^{2}}{\theta} c \equiv \sigma_{C F}^{2} \\
0 & \text { otherwise. }
\end{array}\right.
$$

Next, we compare the above contract with team production ( $T R$-regime). For easier reference, the $T R$ implementation cost per head from $(18)$ is restated:

$$
E C^{T R}=\left\{\begin{array}{ccc}
c-\frac{\sigma^{2}}{2(1-\bar{\theta})} & \text { if } & \sigma^{2} \leq 2(1-\bar{\theta}) c \equiv \sigma_{T R}^{2} \\
0 & \text { otherwise }
\end{array}\right.
$$

The $T R$-regime strictly dominates: i) expected revenue per head is greater by an amount $\bar{\theta}(1-\bar{\theta})$ because coordination failure is averted, and ii) the expected implementation cost is 
(weakly) lower 23

$$
E C^{C F}-E C^{T R}=\left\{\begin{array}{l}
\frac{\sigma^{2}}{2(1+\bar{\theta})}>0 \quad \text { if } \quad \sigma^{2} \leq \sigma_{T R}^{2} \\
E C^{C F} \geq 0 \quad \text { otherwise. }
\end{array}\right.
$$

The only alternative are group-based incentives ( $I R$-regime) which also prevent coordination failure. So whatever the optimal regime is, coordination failure never arises.

Proof of Proposition 3 .

By Proposition 2, the only candidates are team production (TR-regime) and group-based incentives ( $I R$-regime). Both achieve the same expected revenue. By Lemma 3 , the implementation costs for group-based incentives (IR-regime) are $E C^{I R} \in\left(E C^{N B}, \overline{E C}^{I R}\right]$. We restate the upper and lower bounds here:

$$
\begin{aligned}
& \overline{E C}^{I R}=\left\{\begin{array}{ccc}
c-\frac{\sigma^{2}}{1-\bar{\theta}^{2}} & \text { if } & \sigma^{2} \leq \frac{1-\bar{\theta}^{2}}{1+\bar{\theta}(1-\bar{\theta})} c \equiv \sigma_{I R}^{2}, \\
\frac{\bar{\theta}}{1+\bar{\theta}} \sigma^{2} & \text { otherwise, }
\end{array}\right. \\
& E C^{N B}=\left\{\begin{array}{lcc}
c-\frac{\sigma^{2}}{1-\bar{\theta}} & \text { if } & \sigma^{2} \leq(1-\bar{\theta}) c \equiv \sigma_{N B}^{2} \\
0 & \text { otherwise. }
\end{array}\right.
\end{aligned}
$$

Note that $E C^{I R}>0$ for all $\sigma^{2}$ (because $\tau_{i}\left(L_{i}, H_{-i}\right)>0$ ) and that $\sigma_{T R}^{2}>\sigma_{N B}^{2}>\sigma_{I R}^{2}$. Because of this, the cost comparison reduces to two cases:

$$
E C^{T R}-E C^{I R}\left\{\begin{array}{lcc}
\geq E C^{T R}-\overline{E C}^{I R}=\frac{\sigma^{2}}{2(1-\theta)}>0 & \text { if } & \sigma^{2} \leq \sigma_{T R}^{2}=2(1-\bar{\theta}) c \\
=-E C^{I R} & \text { otherwise. }
\end{array}\right.
$$

Thus, no matter which continuation equilibria arise under group-based incentives ( $R$-regime), team production is optimal if and only if $\sigma^{2}>2(1-\bar{\theta}) c \equiv \hat{\sigma}^{2}(c)$.

\section{B More than two ability levels}

We extend here the setting from Section 3 to $N$ possible ability levels $\theta^{n}$, ordered by index $n=1, \ldots, N .: \theta^{1}<\theta^{2}<\cdots<\theta^{N}$. Denote the prior probability that agent $i$ has ability level $\theta^{n}$ by $\alpha^{n} \equiv \operatorname{Prob}\left(\theta_{i}=\theta^{n}\right)$. As in Section 3, the ability level of an agent also describes the maximum input quality that he can achieve for his part of the project. The project has an Oring type technology (Kremer 1993): without coordination the lowest potential input quality (i.e. ability level) among the team members determines the implemented input qualities.

$$
\left(x_{1}, x_{2}\right)=\left(\theta^{\min }, \theta^{\min }\right) \quad \text { without coordination, where } \theta^{\min }=\min \left\{\theta_{1}, \theta_{2}\right\}
$$

\footnotetext{
${ }^{23}$ There are only two cases to consider because $\sigma_{C F}^{2}-\sigma_{T R}^{2}=\frac{(1-\bar{\theta})^{2}}{\bar{\theta}} c>0$.
} 
Coordination allows agents to raise the quality of an implemented input up to its full potential. For example, agent 1 can adapt his project contribution to be compatible with innovative features proposed by the more able team mate 2 . Thus, if $\theta_{1}=\theta^{n_{1}}, \theta_{2}=\theta^{n_{2}}$ and $1 \leq n_{1}<$ $n_{2} \leq N$ the quality of implemented inputs

$$
\left(x_{1}, x_{2}\right) \in\left\{\left(\theta^{n_{1}}, \theta^{n_{1}}\right),\left(\theta^{n_{1}}, \theta^{n_{1}+1}\right), \ldots,\left(\theta^{n_{1}}, \theta^{n_{2}}\right)\right\} \quad \text { if coordination occurs. }
$$

Consider first the $I R$-regime. Suppose that agent 1 is just short of the maximum ability level, $\theta_{1}=\theta^{N-1}$, and the other agent reaches it, $\theta_{2}=\theta^{N}$. The situation mirrors the setting from Section 3 agent 1 cannot gain from coordination and, given that the market expects coordination failure for such a situation, the strict best response of agent 1 is not to coordinate. Specifically, when observing implemented input quality profile $\left(\theta^{N-1}, \theta^{N-1}\right)$ the market allows for the possibility that one of the agents actually has a higher ability level and holds belief

$$
\begin{aligned}
E\left[\theta_{1} \mid x_{1}=\theta^{N-1}, x_{2}=\theta^{N-1}\right] & =\frac{\left(\alpha^{N-1}\right)^{2} \theta^{N-1}+2 \alpha^{N} \alpha^{N-1}\left(\theta^{N}+\theta^{N-1}\right) / 2}{\left(\alpha^{N-1}\right)^{2}+2 \alpha^{N} \alpha^{N-1}} \\
& >E\left[\theta_{1} \mid x_{1}=\theta^{N-1}, x_{2}=\theta^{N}\right]=\theta^{N-1} .
\end{aligned}
$$

The same argument applies for all situations in which the agents turn out to have different ability levels, and we are left with a smoke-screen equilibrium. To show this, work backwards to construct the market beliefs. As we saw, the implemented input quality profile $\left(\theta^{N-1}, \theta^{N-1}\right)$ is associated with the agents indeed both having that ability level or one of them being more able. Profile $\left(\theta^{N-2}, \theta^{N-2}\right)$ hence leaves open the possibilities $\theta_{1}=\theta_{2}=\theta^{N-2}$ as well as $\theta_{1}=\theta^{N-2}$ and $\theta_{2}>\theta^{N-2}$ or $\theta_{2}=\theta^{N-2}$ and $\theta_{1}>\theta^{N-2}$ :

$$
\begin{aligned}
& E\left[\theta_{i} \mid x_{i}=\theta^{N-2}, x_{-i}=\theta^{N-2}\right] \\
& =\frac{\left(\alpha^{N-2}\right)^{2} \theta^{N-2}+2 \alpha^{N} \alpha^{N-2}\left(\theta^{N}+\theta^{N-2}\right) / 2+2 \alpha^{N-1} \alpha^{N-2}\left(\theta^{N-1}+\theta^{N-2}\right) / 2}{\left(\alpha^{N-1}\right)^{2}+2 \alpha^{N} \alpha^{N-2}+2 \alpha^{N-1} \alpha^{N-2}} \\
& =\frac{\left(\alpha^{N-2}\right)^{2} \theta^{N-2}+\operatorname{Prob}\left(\theta_{1} \neq \theta_{2} ; \theta_{1}, \theta_{2} \geq \theta^{N-2}\right) E\left[\left(\theta_{1}+\theta_{2}\right) / 2 \mid \theta_{1} \neq \theta_{2} ; \theta_{1}, \theta_{2} \geq \theta^{N-2}\right]}{\left(\alpha^{N-1}\right)^{2}+\operatorname{Prob}\left(\theta_{1} \neq \theta_{2} ; \theta_{1}, \theta_{2} \geq \theta^{N-2}\right)},
\end{aligned}
$$

Again, coordination failure leads to a higher reputation than being alone in contributing the relatively lower quality input $x_{i}=\theta^{N-2}: E\left[\theta_{i} \mid x_{i}=\theta^{N-2}, x_{-i}>\theta^{N-2}\right]=\theta^{N-2}$. By induction, therefore for implemented input quality profile $\left(\theta^{n}, \theta^{n}\right), 1 \leq n<N$,

$$
\begin{aligned}
E\left[\theta_{i} \mid x_{i}=\theta^{n}, x_{-i}=\theta^{n}\right] & =\frac{\left(\alpha^{n}\right)^{2} \theta^{n}+\operatorname{Prob}\left(\theta_{1} \neq \theta_{2} ; \theta_{1}, \theta_{2} \geq \theta^{n}\right) E\left[\left(\theta_{1}+\theta_{2}\right) / 2 \mid \theta_{1} \neq \theta_{2} ; \theta_{1}, \theta_{2} \geq \theta^{n}\right]}{\left(\alpha^{n}\right)^{2}+\operatorname{Prob}\left(\theta_{1} \neq \theta_{2} ; \theta_{1}, \theta_{2} \geq \theta^{n}\right)} \\
& >E\left[\theta_{i} \mid x_{i}=\theta^{n}, x_{-i}>\theta^{n}\right]=\theta^{n} .
\end{aligned}
$$

It is straightforward that under the $T R$-regime both agents gain in terms of reputation whenever the average quality of the project inputs increases. Hence, agents always coordinate to implement the highest possible quality level: $(x, x)=\left(\theta_{1}, \theta_{2}\right)$. Thus, we can conclude that Proposition 1 extends to this setting. 


\section{Additional signal available about coordination}

Lacking cooperation in a group often produces signs of stress or conflict. Section 3 assumed such signals are not observed by the market. Suppose now that in case of coordination failure the market observes such a 'stress' signal $S=C F$ in addition to the project outcome. Therefore, in the absence of evidence for coordination failure, a low-quality group outcome under the $I R$-regime can only be attributed to lack of ability, so $E\left[\theta_{i} \mid L_{1}, L_{2}, S=\emptyset\right]=\theta^{L}$. However, with such evidence $E\left[\theta_{i} \mid L_{1}, L_{2}, S=C F\right]>\theta^{L}$ if the market places at least some probability on coordination to fail when an agent is less successful than his project partner. This makes it a strict best response for an agent to create this 'stress' signal whenever he cannot contribute a high-quality input. So on the equilibrium path, the outcome $\left(L_{1}, L_{2}\right)$ always occurs in conjunction with $S=C F$ and equilibrium beliefs are just as in Section 3 .

Again, team production guarantees coordination will occur because it removes the reputational source of conflict. The argument is more subtle though: one needs to rule out the possibility of a self-fulfilling expectation by the market that coordination fails in the presence of highquality inputs. To show that such a belief unravels and cannot be an equilibrium, suppose the market always expected coordination failure. Then it is still a strict best response for agents to coordinate if they both have a high-quality input because $E\left[\theta_{i} \mid L_{1}, L_{2}, S=C F\right]<\theta^{H}$. Now, if the market expected that coordination failure occurs unless both agents have a high-quality input, $E\left[\theta_{i} \mid L, L, S=C F\right]$ would be equal to $E\left[\theta_{i} \mid L_{1}, L_{2}\right]$ from (1) in Section 3 . But, in this case too, it is a strict best response to reveal that one team member has high ability because Section 3 shows that $E\left[\theta_{i} \mid L, H\right]>E\left[\theta_{i} \mid L_{1}, L_{2}\right]$. Thus, in any equilibrium team members always coordinate to implement high-quality inputs. So, Proposition 1 extends to this setting.

\section{Asymmetric priors}

In many circumstances project members will differ in characteristics such as age, experience, and education. As we discuss here, this however has no effect on the structure of the coordination problem. Suppose, without loss of generality, that agent 1 has a better prior reputation than agent 2, i.e. $\alpha_{1}>\alpha_{2}$. By the same argument as in Section 3 , there is coordination failure when only one agent has access to a high-quality input: the other agent can never improve his reputation by coordinating and thus has nothing to gain. All that changes is that in the resulting smoke-screen equilibrium we have different posteriors when no high-quality inputs are implemented,

$$
E\left[\theta_{i} \mid L_{1}, L_{2}\right]=\theta^{L}+\frac{\alpha_{i}\left(1-\alpha_{-i}\right)}{1-\alpha_{i} \alpha_{-i}}\left(\theta^{H}-\theta^{L}\right)
$$


Coordination under the $T R$-regime is not affected by this change in information structure. But posteriors here, too, now also depend on the prior about an agent:

$$
E\left[\theta_{i} \mid L, H\right]=\theta^{L}+\frac{\alpha_{i}\left(1-\alpha_{-i}\right)}{\alpha_{1}\left(1-\alpha_{2}\right)+\alpha_{2}\left(1-\alpha_{1}\right)}\left(\theta^{H}-\theta^{L}\right) .
$$

\section{E Implemented inputs are only observed after a success}

Implemented inputs in a project may in some cases only be observable in case of a successful outcome (e.g. patents, academic publications). To capture this, we modify here the setup from Section 3 by assuming that the project outcome can either be a success $(y=1)$ or a failure $(y=0)$. The probability of the project succeeding depends on the quality of implemented inputs $x_{1}, x_{2}$. Denote this by $p_{x_{1} x_{2}} \equiv \operatorname{Prob}\left(y=1 \mid x_{1}, x_{2}\right)$, and suppose that $1 \geq p_{H H}>p_{L H}=$ $p_{H L}>p_{L L} \geq 0$. If the project succeeds, project inputs are observed. Otherwise it is only known that the project failed. As in Section 3 , the project affects the agents' reputation but has no other direct monetary payoff.

As it turns out, this information structure only reinforces the result from Proposition 1 that there is coordination failure with individual records. We build some intuition for this before proceeding to show the result formally. Suppose agent 2 only has a low-quality input. If $y=1$, inputs are revealed and agent 2 only has low quality to show. In contrast, there is no information about inputs if $y=0$. Because in the latter case the market factors in the possibility that agent 2 might have had a high-quality input and just was unlucky, his reputation following $y=0$ is higher than if $y=1$. From his perspective it is therefore optimal to reduce the chances of the outcome $y=1$ by not coordinating to implement his team mate's high-quality input.

To show the argument formally suppose, by way of contradiction, that market participants expect team members to always coordinate and implement high-quality inputs. Then, $E\left[\theta_{i} \mid L_{1}, L_{2} ; y=1\right]^{C}=E\left[\theta_{i} \mid L_{i}, H_{-i} ; y=1\right]^{C}=\theta^{L}$, where superscript $C$ indicates that the reputation was derived using the coordination presumption of the market. Moreover,

$$
\begin{aligned}
\operatorname{Prob}(y=1)^{C}=\alpha^{2} p_{H H}+ & 2 \alpha(1-\alpha) p_{L H}+(1-\alpha)^{2} p_{L L} \text {. Hence, } \\
E\left[\theta_{i} \mid y=0\right]^{C}= & \frac{\alpha^{2}\left(1-p_{H H}\right) \theta^{H}+2 \alpha(1-\alpha)\left(1-p_{L H}\right)\left(\theta^{L}+\theta^{H}\right) / 2}{1-\operatorname{Prob}(y=1)^{C}} \\
& +\frac{(1-\alpha)^{2}\left(1-p_{L L}\left(1-p_{L H}\right) \theta^{L}\right.}{1-\operatorname{Prob}(y=1)^{C}} \\
= & \theta^{L}+\frac{\alpha^{2}\left(1-p_{H H}\right)+\alpha(1-\alpha)\left(1-p_{L H}\right)}{\operatorname{Prob}(y=0)^{C}}\left(\theta^{H}-\theta^{L}\right) \\
> & E\left[\theta_{i} \mid L_{1}, L_{2} ; y=1\right]^{C}=E\left[\theta_{i} \mid L_{i}, H_{-i} ; y=1\right]^{C}=\theta^{L} .
\end{aligned}
$$


As a result, the success state is less desirable for an agent with a low-quality input than $y=0$. His strict best response therefore is not to coordinate and thereby reduce the chance of outcome $y=1$ from $p_{L H}$ to $p_{L L}$. This contradicts market beliefs.

To show that the smoke-screen equilibrium indeed exists, suppose now that the market expects coordination failure unless both team members develop high-quality inputs. A useful short cut for computations is to notice that whenever we face a situation with implemented inputs $\left(L_{1}, L_{2}\right)$, be they visible $(y=1)$ or not $(y=0)$, the expected ability of an agent is equal to $E\left[\theta_{i} \mid L_{1}, L_{2}\right]$ from equation (1) in Section 3 . Denoting reputations derived under the coordination failure presumption with superscript $C F$, we have

$$
\begin{aligned}
E\left[\theta_{i} \mid L_{1}, L_{2} ; y=1\right]^{C F} & =\theta^{L}+\frac{\alpha}{1+\alpha}\left(\theta^{H}-\theta^{L}\right)=\bar{\theta}-\frac{\alpha^{2}}{1+\alpha}\left(\theta^{H}-\theta^{L}\right) \\
& >E\left[\theta_{i} \mid L_{i}, H_{-i} ; y=1\right]^{C F}=\theta^{L} .
\end{aligned}
$$

The expected success probability now is $\operatorname{Prob}(y=1)^{C F}=\alpha^{2} p_{H H}+\left(1-\alpha^{2}\right) p_{L L}$, and

$$
\begin{aligned}
& E\left[\theta_{i} \mid y=0\right]^{C F}=\frac{\alpha^{2}\left(1-p_{H H}\right) \theta^{H}+\left(1-\alpha^{2}\right)\left(1-p_{L L}\right) E\left[\theta_{i} \mid L_{1}, L_{2} ; y=1\right]^{C F}}{\operatorname{Prob}(y=0)^{C F}} \\
= & E\left[\theta_{i} \mid L_{1}, L_{2} ; y=1\right]^{C F}+\frac{\alpha^{2}\left(1-p_{H H}\right)}{\operatorname{Prob}(y=0)^{C F}}\left(\theta^{H}-E\left[\theta_{i} \mid L_{1}, L_{2} ; y=1\right]^{C F}\right) \\
> & E\left[\theta_{i} \mid L_{1}, L_{2} ; y=1\right]^{C F} .
\end{aligned}
$$

We thus conclude that it is a best response for an agent with a low-quality input not to coordinate. First, this increases the reputation that the agent has conditional on being in state $y=1: E\left[\theta_{i} \mid L_{1}, L_{2} ; y=1\right]^{C F}>E\left[\theta_{i} \mid L_{i}, H_{-i} ; y=1\right]^{C F}$. Second, this increases the chances of being in state $y=0$, which provides the highest possible reputation that the agent can hope to achieve: $E\left[\theta_{i} \mid y=0\right]^{C F}>E\left[\theta_{i} \mid L_{1}, L_{2} ; y=1\right]^{C F}$.

As is straightforward to verify, coordination under the $T R$-regime is not affected by this change in information structure. Both agents can only gain from increasing the average expected ability of a team member by implementing high-quality inputs.

\section{References}

Alchian, A. A., And H. Demsetz (1972): "Production, Information Costs, and Economic Organization," American Economic Review, 62(5), 777-95.

Auriol, E., G. Friebel, And L. Pechlivanos (2002): "Career Concern in Teams," Journal of Labor Economics, 20(1), 289-307.

Autor, D. H., L. F. Katz, and M. S. Kearney (2008): “Trends in U.S. Wage Inequality: Revising the Revisionists," Review of Economics and Statistics, 90(2), 300-323. 
Baliga, S., And T. Sjöström (2001): "Optimal Design of Peer Review and Self-Assessment Schemes," RAND Journal of Economics, 32(1), 27-51.

BAR-IsaAC, H. (2007): "Something to Prove: Reputation in Teams," RAND Journal of Economics, 38(2), 495-511.

Bartel, A. P., and N. Sicherman (1999): "Technological Change and Wages: An Interindustry Analysis," Journal of Political Economy, 107(2), 285-325.

Boning, B., C. Ichniowski, and K. Shaw (2007): "Opportunity Counts: Teams and the Effectiveness of Production Incentives," Journal of Labor Economics, 25(4), 613-650.

Bresnahan, T. F., E. Brynjolfsson, and L. M. Hitt (2002): "Information Technology, Workplace Organization, and the Demand for Skilled Labor: Firm-Level Evidence," Quarterly Journal of Economics, 117(1), 339-376.

Card, D., and J. E. DiNardo (2002): "Skill-Biased Technological Change and Rising Wage Inequality: Some Problems and Puzzles," Journal of Labor Economics, 20(4), 733-783.

Caroli, E., and J. V. Reenen (2001): "Skill-Biased Organizational Change? Evidence from a Panel of British and French Establishments," Quarterly Journal of Economics, 116(4), 1449-1492.

Che, Y.-K., And S.-W. Yoo (2001): "Optimal Incentives for Teams," American Economic Review, 91(3), 525-541.

Chen, K.-P. (2003): "Sabotage in Promotion Tournaments," Journal of Law, Economics, and Organization, 19(1), 119-140.

Corts, K. S. (2008): "Teams vs. Individual Accountability: Solving Multi-Task Problems Through Job Design," RAND Journal of Economics, 38(2), 467 - 479.

Cremer, J. (1995): “Arm's Length Relationships," Quarterly Journal of Economics, 110(2), $275-95$.

Demougin, D., And C. Fluet (1998): "Mechanism Sufficient Statistic in the Risk-Neutral Agency Problem," Journal of Institutional and Theoretical Economics, 127(4), 622-639.

Despres, C., And J.-M. Hiltrop (1995): "Human Resource Management in the Knowledge Age: Current Practice and Perspectives on the Future," Employee Relations, 17(1), 9 - 23. 
Dewatripont, M., I. Jewitt, and J. Tirole (1999a): "The Economics of Career Concerns, Part I: Comparing Information Structures," Review of Economic Studies, 66, 183-198.

(1999b): "The Economics of Career Concerns, Part II: Application to Missions and Accountability of Government Agencies," Review of Economic Studies, 66, 199-217.

FAmA, E. F. (1980): "Agency Problems and the Theory of the Firm," Journal of Political Economy, 88(2), 288-307.

Faraj, S., And L. Sproull (2000): "Coordinating Expertise in Software Development Teams," Management Science, 46(12), 1554-1568.

Foray, D. (2004): The Economics of Knowledge. MIT Press, Cambridge, MA.

Fudenberg, D., And J. Tirole (1986): Game Theory. MiT Press, Cambridge, MA.

Galor, O., And O. MoAv (2000): “Ability-Biased Technological Transition, Wage Inequality, and Economic Growth," Quarterly Journal of Economics, 115(2), 469-497.

Gibbons, R. (2003): "Team Theory, Garbage Cans and Real Organizations: Some History and Prospects of Economic Research on Decision-Making in Organizations," Industrial and Corporate Change, 12(4), 753-787.

Gibbons, R., And K. J. Murphy (1992): "Optimal Incentive Contracts in the Presence of Career Concerns: Theory and Evidence," Journal of Political Economy, 100(3), 468-505.

Green, J. R., And N. L. Stokey (1983): "A Comparison of Tournaments and Contracts," Journal of Political Economy, 91(3), 349-364.

Hamilton, B. H., J. A. Nickerson, and H. Owan (2003): "Team Incentives and Worker Heterogeneity: An Empirical Analysis of the Impact of Teams on Productivity and Participation," Journal of Political Economy, 111(3), 465-497.

Hayton, J. C. (2005): "Promoting Corporate Entrepreneurship Through Human Resource Management Practices: A Review of Empirical Research," Human Resource Management Review, 15(1), 21-41.

Hemmer, T. (1995): "On the Interrelation Between Production Technology, Job Design, and Incentives," Journal of Accounting and Economics, 19(2-3), 209-245.

Holmström, B. (1979): "Moral Hazard and Observability," Bell Journal of Economics, 10, $74-91$. 
(1982): "Moral Hazard in Teams," Bell Journal of Economics, 13, 324-340.

(1982/99): "Managerial Incentive Problems: A Dynamic Perspective," Review of Economic Studies, 66, 169-182, ; originally published in: Essays in Economics and Management in Honour of Lars Wahlbeck, Helsinki, Finland.

IChniowski, C., And K. Shaw (2003): "Beyond Incentive Pay: Insiders Estimates of the Value of Complementary Human Resource Management Practices," Journal of Economic Perspectives, 17(1), 155-180.

Ітон, H. (1991): "Incentives to Help in Multi-Agent Situations," Econometrica, 59(3), 611636.

Janssen, O., E. Van de Vliert, and M. West (2004): "The Bright and Dark Sides of Individual and Group Innovation: A Special Issue Introduction," Journal of Organizational Behavior, 25(2), 129-145.

JEOn, S. (1996): "Moral Hazard and Reputational Concerns in Teams: Implications for Organizational Choice," International Journal of Industrial Organization, 14, 297-315.

Juhn, C., K. M. Murphy, And B. Pierce (1993): "Wage Inequality and the Rise in Returns to Skill," Journal of Political Economy, 101(3), 410-42.

Koch, A. K., And E. Peyrache (2008a): “Aligning Ambition and Incentives," University of Aarhus Economics Working Paper 2008-16.

(2008b): "Mixed Up? That's Good for Motivation," Economic Theory, 34(1), 107125.

Kremer, M. (1993): "The O-Ring Theory of Economic Development," Quarterly Journal of Economics, 108(3), 551-75.

Laffont, J.-J., And D. Martimort (2002): The Theory of Incentives: The Principal-Agent Model. Princeton University Press, Princeton, NJ.

LAwler, E. E. I. (2003): "Reward Systems in the Knowledge-based Organizations," in Managing Knowledge for Sustained Competitive Advantage, ed. by S. E. Jackson, M. A. Hitt, and A. DeNisi, pp. 274-302. Jossey-Bass, San Francisco.

Lawler, E. E. I., S. Mohrman, and G. J. Ledford (1995): Creating High Performance Organizations: Practices and Results in the Fortune 1000. Jossey-Bass, San Francisco. 
Lazear, E. (1989): "Pay Equality and Industrial Politics," Journal of Political Economy, $97(3), 561-580$.

Lazear, E. P., and S. Rosen (1981): "Rank-Order Tournaments as Optimum Labor Contracts," Journal of Political Economy, 89(5), 841-864.

Marschak, J., And R. Radner (1972): Economic Theory of Teams. Yale University Press, New Haven.

Meyer, M. A., T. E. Olsen, And G. TorsviK (1996): "Limited Intertemporal Commitment and Job Design," Journal of Economic Behavior and Organization, 31(3), 401- 417.

Meyer, M. A., And J. ViCKers (1997): "Performance Comparisons and Dynamic Incentives," Journal of Political Economy, 105(3), 547-581.

Mohrman, S. A., S. G. Cohen, and J. Mohrman, Allan M. (1995): Designing TeamBased Organizations: New Forms for Knowledge Work. Jossey-Bass, San Francisco.

MookherJee, D. (1984): "Optimal Incentive Schemes with Many Agents," Review of Economic Studies, 51(3), 433-46.

MukherJee, A. (2008): "Sustaining Implicit Contracts When Agents Have Career Concerns: The Role of Information Disclosure," RAND Journal of Economics, 39, 469-490.

Murnane, R. J., J. B. Willett, and F. Levy (1995): "The Growing Importance of Cognitive Skills in Wage Determination," Review of Economics and Statistics, 77(2), 251266.

Nalebuff, B. J., And J. E. Stiglitz (1983): "Prizes and Incentives: Towards a General Theory of Compensation and Competition," Bell Journal of Economics, 14(1), 21-43.

Nonaka, I. (1991): "The Knowledge-Creating Company," Harvard Business Review, November, 96-104.

Nonaka, I., And H. TAKeuchi (1995): The Knowledge Creating Company. Oxford University Press, Oxford.

OECD (1996): "The Knowledge-based Economy," in 1996 Science, Technology and Industry Outlook. OECD, Paris.

(2001): Science, Technology and Industry Scoreboard 2001. Paris. 
Ortega, J. (2003): "Power in the Firm and Managerial Career Concerns," Journal of Economics and Management Strategy, 12(1), 1-29.

Osterman, P. (1994): "How Common is Workplace Transformation and Who Adopts it?," Industrial and Labor Relations Review, 47(2), 173-188.

(2000): "Work Reorganization in an Era of Restructuring: Trends in Diffusion and Effects on Employee Welfare," Industrial and Labor Relations Review, 53(2), 179-196.

Paulus, P. B., And H.-C. YAng (2000): "Idea Generation in Groups: A Basis for Creativity in Organizations," Organizational Behavior and Human Decision Processes, 82(1), 76-87.

Polanyi, M. (1966): The Tacit Dimension. Doubleday, Garden City, NY.

Prat, A. (2005): "The Wrong Kind of Transparency," American Economic Review, 95(3), $862-877$.

Selten, R. (1975): "Reexamination of the Perfectness Concept for Equilibrium Points in Extensive Games," International Journal of Game Theory, 4(1), 25-55.

Thompson, J. (1967): Organizations in Action. McGraw-Hill, New York, NY.

Wageman, R. (1995): "Interdependence and Group Effectiveness," Administrative Science Quarterly, 40(1), 145-180.

West, M. A. (2002): "Sparkling Fountains or Stagnant Ponds: An Integrative Model of Creativity and Innovation Implementation in Work Groups," Applied Psychology, 51(3), $355-387$.

West, M. A., And K. G. Tuosvold, D.And Smith (eds.) (2003): International Handbook of Teamwork and Cooperative Working. Wiley, Chichester. 